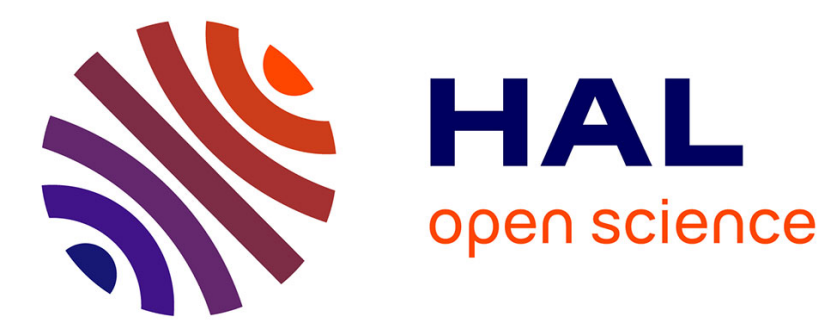

\title{
Fracture of glassy polymers within sliding contacts
}

\author{
Antoine Chateauminois, Marie-Christine Baietto
}

\section{To cite this version:}

Antoine Chateauminois, Marie-Christine Baietto. Fracture of glassy polymers within sliding contacts. Intrinsic Molecular Mobility and Toughness of Polymers II, 188, pp.153-193, 2005, Advances in Polymer Science, 3-540-26162-1. 10.1007/b136979 . hal-01951574

\section{HAL Id: hal-01951574 \\ https://hal.science/hal-01951574}

Submitted on 7 Jul 2021

HAL is a multi-disciplinary open access archive for the deposit and dissemination of scientific research documents, whether they are published or not. The documents may come from teaching and research institutions in France or abroad, or from public or private research centers.
L'archive ouverte pluridisciplinaire HAL, est destinée au dépôt et à la diffusion de documents scientifiques de niveau recherche, publiés ou non, émanant des établissements d'enseignement et de recherche français ou étrangers, des laboratoires publics ou privés.

\section{(c)(1)}

Distributed under a Creative Commons Attribution| 4.0 International License 


\title{
Fracture of Glassy Polymers Within Sliding Contacts
}

\author{
Antoine Chateauminois ${ }^{1}(\bowtie) \cdot$ Marie Christine Baietto-Dubourg $^{2}$ \\ ${ }^{1}$ Laboratoire de Physico-Chimie des Polymères et des Milieux Dispersés, PPMD, CNRS \\ UMR 7615, Ecole Supérieure de Physique et Chimie Industrielles (ESPCI), 10 rue \\ Vauquelin, 75231 Paris Cedex 5, France \\ antoine.chateauminois@espci.fr \\ ${ }^{2}$ Laboratoire de Mécanique des Contacts et des Solides, LAMCOS, CNRS UMR 5514, \\ INSA de Lyon, 20 Avenue A. Einstein, Villeurbanne Cedex, France \\ Marie-Christine.baietto@insa-lyon.fr
}

\begin{abstract}
Cracking processes in brittle amorphous polymers within sliding contacts and their relationships with bulk fracture properties are reviewed. The focus is on the use of model single asperity contacts to mimic and characterize the failure modes which can be encountered at the microasperity level during the wear of macroscopic rough contacts between polymer surfaces and rigid counterfaces. Using the resources of in situ contact visualization, crack initiation and propagation mechanisms within epoxy substrates are detailed under contact fatigue conditions. With the prospect of understanding the fundamental mechanisms involved in particles detachment from brittle polymer surfaces, it is shown how cracks locations, orientations and depths can be predicted from a knowledge of the bulk toughness and fatigue properties of the polymer by means of a fracture mechanics analysis of the contact. In the last section, the sensitivity of contact fatigue processes to molecular parameters is addressed in the case of anti-plasticized epoxy networks and random copolymers of poly(methylmethacrylate).
\end{abstract}

Keywords Contact fatigue $\cdot$ Toughness Fatigue properties . Wear 


\section{Abbreviations}

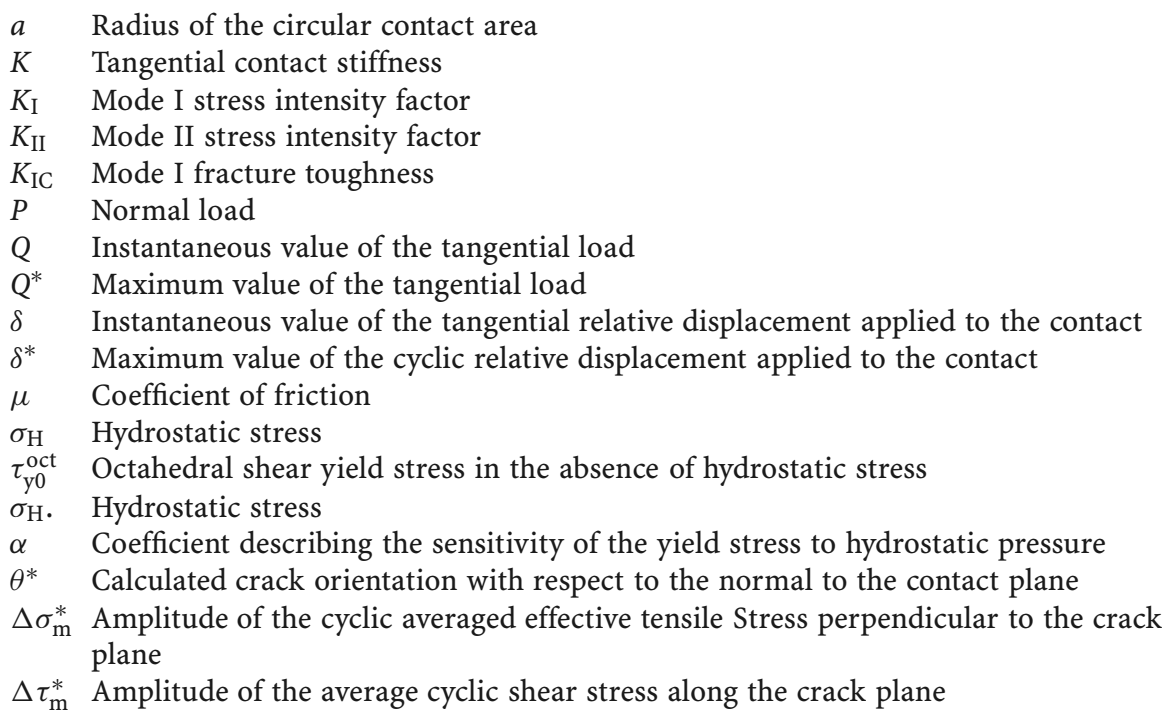

\section{1}

\section{Introduction}

The topic of polymer wear and its relationships with mechanical properties has a long history that has been reviewed by several authors (see [1-6] for instance). From an historical point of view, wear processes within polymer materials have been essentially considered within the context of macroscopic contacts between rough surfaces sliding past each other. In such situations, the action of mechanical forces and/or chemical effects at discrete microcontacts between the surface asperities result in localized surface damage and the subsequent production of debris particles from one or both of the contacting surfaces. However, these failure processes are not monomechanistic and involve a sequence of often ill defined and interacting processes which are sensitive to several parameters such as contact loading conditions, surface roughness, material mechanical and physico-chemical properties, environment... Following early studies on the wear of metallic materials, phenomenological classifications based on some perceived judgments of the origins and consequences of particle detachment processes from polymer surfaces have been proposed in the literature $[1,2]$. On the basis of microscopic observations of worn surfaces, "abrasion", "transfer wear", "chemical wear", "erosion", "fatigue wear", etc. have been pointed out as potential and 
often interacting wear modes. In order to rationalize the various descriptions of wear damage, Briscoe $[3,4]$ has proposed a generic scaling approach which emerges from the accepted value of the two-term non-interacting model of friction proposed by Tabor [7]. In this latter model, energy dissipation associated with friction, as a first approximation, is assumed to arise from two separate contributions: (1) an interfacial component (often denoted the "adhesive" component of friction), which is associated with the shearing of the adhesive junctions formed between contacting microasperities within macroscopic contacts, and (2) a bulk "ploughing" component which corresponds to the mechanical losses induced by the deformation of the softer material by the sliding asperities of the harder material.

If one considers that wear damage also results in energy dissipation, this approach can tentatively be applied to wear. Accordingly, wear processes can be classified as "cohesive" or "interfacial" depending on the length scales associated with particles detachment mechanisms (Fig. 1).

Adhesive, or transfer wear has long been recognized as a major source of wear in semi-crystalline polymers such as polytetrafluoroethylene (PTFE) and ultra high molecular weight polyethylene (UHMWPE), where friction is known to induce the transfer to the sliding counterface of highly oriented films a few tens of nanometres in thickness [8-13]. The shear work associated with the formation of such transfer films is dissipated within confined layers close to the sliding interface, where the strain rates and levels are far beyond those accessible by conventional bulk mechanical testing. In many cases, this naturally creates a significant increase in local temperature, which, in association with localized shear, can give rise to tribochemical degradation processes such as chain scission [14].

On the other hand, the general feature of cohesive wear is that frictional work is dissipated within a relatively thick surface zone either through the interaction of surface forces and the resultant traction stresses or simply via geometrical interlocking of interpenetrating contacts. Typically, these zones will be of a thickness which is of the order of a contact length. Within a macroscopic contact between rough surfaces, a small contact length of a few micrometres will be associated with the discrete asperity contacts and a longer length will be defined from the apparent (macroscopic) contact area. As opposed to interfacial modes, cohesive wear involves relatively mild viscoelastic or viscoplastic deformations which are to some extent accessible to bulk mechanical characterization, provided that the contact stress conditions are readily identified.

This crude distinction between adhesive and cohesive wear mechanisms is probably oversimplified in the sense that it neglects many aspects of the interactions between bulk deformation modes and interface rheology. It has, however, the merit of making a clear distinction between wear processes which can, to some extent, be related to known bulk failure properties and 


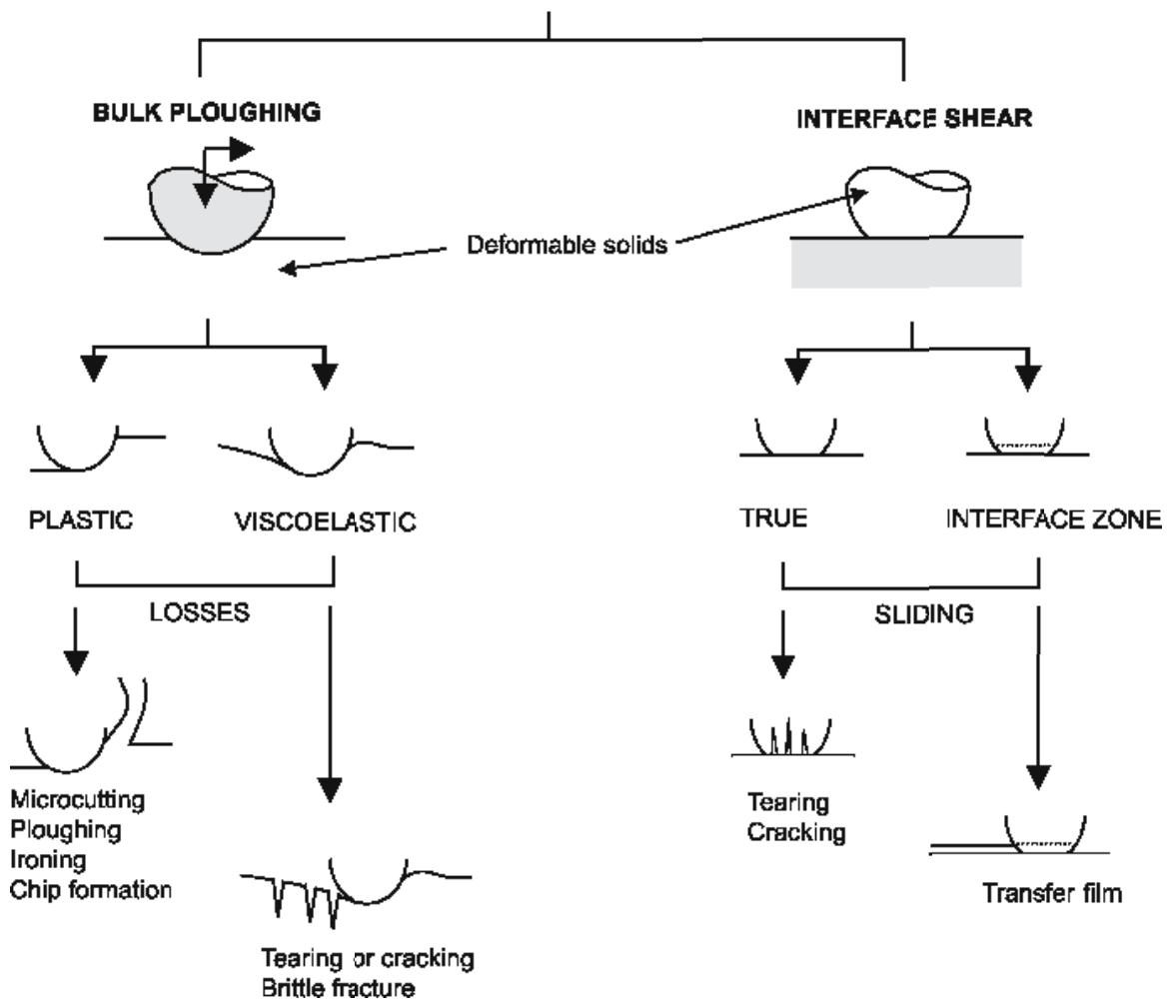

Fig. 1 Schematic description of "cohesive" and "interfacial" wear processes from the two terms non interacting model of friction (from [96]). Bulk ploughing involves the dissipation of the frictional work within a volume of the order of the cube of the contact radius. Interfacial shear corresponds to the dissipation of the frictional energy in much thinner regions and at greater energy densities. Cohesive wear processes (cracking, tearing, microcutting...) are governed by the cohesive strength of the polymer. Mechanisms such as transfer film formation correspond to interfacial wear and do not readily correlate with accessible bulk failure properties

more intense wear mechanisms which do not readily correlate with accessible bulk mechanical properties.

The relevance of bulk fracture properties has therefore been considered essentially within the context of cohesive wear modes such as abrasive and fatigue wear. During abrasive wear, the initial stage is considered to be the process of contact and scratch between the polymer surface and a sharp asperity. The accumulation of the associated microscopic failure events eventually generates wear particles and gives rise to weight loss. Early approaches initiated by Ratner and co-workers [15] and Lancaster [16] attempted to correlate the abrasive wear rate with some estimate of the work to failure of the 
same polymer. Using several semi-crystalline and glassy amorphous polymers with tensile works to rupture ranging over more than two orders of magnitude, they indeed showed the existence of a roughly linear relationship between the measured abrasive wear rates and the reciprocal of the work to failure. Owing to the lack of information regarding the nature of the microscopic deformation and failure processes, several doubts surround, however, the value of this correlation when a more detailed analysis of the relationships between abrasive wear and bulk mechanical properties is considered. It is especially unclear whether fatigue properties rather than the fracture energy involved in a single cracking event should be considered. The occurrence of fatigue processes induced by the repeated sliding of rigid asperities on elastically deforming polymer surfaces has indeed often been pointed out as a potential source of wear damage in many brittle polymers. Accordingly, macroscopic fatigue wear models have been derived [2, 17-19] which attempt to correlate the wear rates with an estimate of the number of cycles to detach a particle from the polymer surface. The latter is usually assessed from a knowledge of bulk fatigue properties and from some estimate of the distribution of the localized tensile stresses which are generated at the microasperity level. Alternatively, models of fatigue wear approach the problem from the standpoint of fracture mechanics $[2,17]$. The wear rate is assumed to be inversely proportional to the number of cycles to failure and this can be derived by integrating the Paris equation for fatigue crack growth. Although such models can account for the effects of parameters such as surface roughness or environment in stress corrosion cracking conditions, the lack of information regarding crack orientation and propagation rates at the microscopic level precludes any more quantitative analysis of fatigue wear processes.

In addition to the difficulties associated with the identification of the deformation and failure processes, the analysis of wear processes within macroscopic contacts between rough surfaces can also be complicated by the behaviour of the wear debris trapped at the sliding interfaces. Once detached, the debris particles are invariably subjected to a variety of processes such as comminution, chemical reactions, aggregation and compaction and ultimately form what is often called a "third body" [20,21]. It is now widely acknowledged that the third body rheology at the sliding interface can significantly affect the mechanical stressing of the rubbing surfaces and modify the associated particle detachment mechanisms. In poly(methylmethacrylate)/steel contacts, it has, for example, been shown that specific contact zone kinematics conditions can result in the accumulation of polymeric debris particles within distinct and highly coherent third body agglomerates [22-24]. Such situations are associated with a strong decrease in the wear damage as a substantial part of the frictional energy is dissipated through the shearing of the third body which acts as a solid lubricant. 
These observations underline the strongly intricate interactions between particle detachment, third body rheology and evolving contact conditions which are inherent to wear processes in many macroscopic contacts.

In order to overcome the above-mentioned inherent limitations of macroscopic, multi-asperity contacts for the fundamental investigation of wear processes, model experiments that attempt to simulate the damage induced by a single asperity contact are often considered. Although the wear rate itself is not monitored, such experiments provide the opportunity to get a more detailed insight into the deformation and fracture mechanisms involved in asperity engagements [25]. The recent emergence of hardness and nanoscratching probes has provided the opportunity to investigate these processes at length scales which are comparable with those involved in typical sliding contacts. Alternatively, single asperity contacts at larger scales offer the possibility of investigating the dynamics of contact failure using the resources of in situ visualization. Both approaches will be reviewed in the subsequent sections, with an emphasis on the use of single asperity contact to investigate contact fatigue processes in relation to fatigue and toughness properties.

Within this context, the analysis will be focused on brittle amorphous polymers such as epoxies and acrylates, whose tribological damage in sliding contacts is known to be dominated by cracking micromechanisms. Such materials are relevant to many tribological applications. Fibre-reinforced composites with thermoset matrices are, for example, used as seal gear and dry bearing materials $[26,27]$. Similarly, contact deformation and fracture processes of acrylate-based coatings can be a concern regarding wear and scratch resistance properties of optical coatings and varnishes [28-30]. Within the context of this review, these materials will, however, mostly be considered as model polymer systems which allow some insight into the fundamental mechanisms of crack nucleation and growth within contacts. Such an approach would be much more complicated using more ductile engineering polymers for tribological applications, such as polyamides or polyoxymethylene, where the in situ analysis of cracking processes is limited by transfer film formation and extensive plastic flow.

\section{2}

\section{Overview of Experimental Approaches of Fracture Mechanisms Within Single Asperity Contacts}

\section{1}

\section{Micro/Nano Scratching Techniques}

Since the early work from Schallamach [31] on the wear processes of rubbers, indentation and scratching experiments have been largely used to mimic 
and characterize the deformation and failure modes which occur as a consequence of specific interactions between asperities touching each other in discrete areas of the contact between rough polymeric solids. Although it does not model the dynamic asperity interactions encountered in practical tribological contacts, any form of scratch hardness can be viewed as a form of controlled abrasive wear. Extrapolation of scratch tests to wear situations must, however, be done with some caution as the geometry of the scratch indenter is likely to be different (usually very much more severe) from those of the asperities that make up the topography of even comparatively rough surfaces. Moreover, scratch tests are unable to reproduce fatigue failure events, which have long been recognized as a potential source of particle detachment in many practical wear situations involving polymers.

From a more fundamental point of view, the selection of different indenter geometries and loading conditions offer the possibility of exploring the viscoelastic/viscoplastic response and brittle failure mechanisms over a wide range of strain and strain rates. The relationship between imposed contact strain and indenter geometry has been quite well established for normal indentation. In the case of a conical or pyramidal indenter, the mean contact strain is usually considered to depend on the contact slope, $\theta$ (Fig. 2a). For metals, Tabor [32] has established that the mean strain is about $0.2 \tan \theta$, i.e. independent of the indentation depth. A similar relationship seems to hold for polymers although there is some indication that the proportionality could be lower than 0.2 for viscoelastic materials $[33,34]$. In the case of a sphere, an

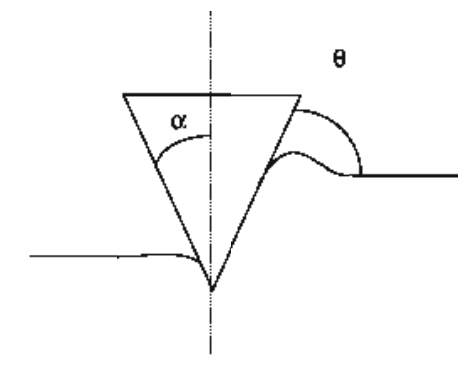

(a)

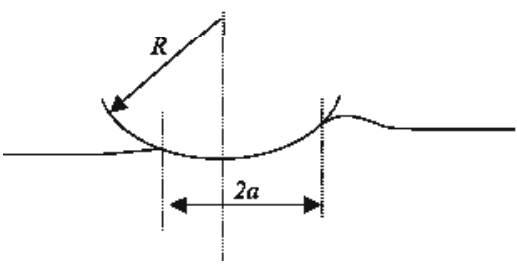

(b)

Fig. 2 Typical contact geometries used for scratch testing. The average strain is proportional $\mathbf{a}$ to $\tan \theta$ in the case of conical or pyramidal indentors and $\mathbf{b}$ to $a / R$ in the case of spherical indentors 
indentation depth-dependent strain can be defined as the ratio of the contact radius to the sphere radius (Fig. 2b). Similarly, an average strain rate can be defined by dividing the sliding speed by some characteristic length, usually the width of the permanent groove left on the polymer surface. Typical mean strain values during scratch tests lie in the range $5-10 \%$ and the strain rate can be varied from $10^{-4} \mathrm{~s}^{-1}$ to $10^{2} \mathrm{~s}^{-1}$ in most of the commercially available scratching equipments.

Topographical characterizations using SEM, AFM or laser reflectivity are usually associated with tangential force measurements in order to assess the various regimes of deformation. The observed damage evolves through a range of severity as the contact strain is increased: viscoelastic smoothing or "ironing", plastic or viscoplastic grooving, extensive plastic flow and tearing, pronounced fracture or tearing and finally cutting or chip formation can be identified using glassy polymers such as poly(methylmethacrylate) or polycarbonate.

These approaches have been especially popularized for a variety of amorphous and glassy and semi-crystalline polymers by Briscoe and coworkers [25,34-37], who put together in the form of "deformation maps" the different deformation regimes. The indenter angle and the penetration depth (or normal load) are usually considered the key parameters. Figure 3 provides an example of such a scratching map for polycarbonate using a conical indenter. It can be seen that, taking an arbitrary constant load, the nature of the contact damage can change from viscoplastic deformation ("ductile ploughing") to brittle crack propagation when the indenter angle is decreased, i.e. when the contact strain is increased.

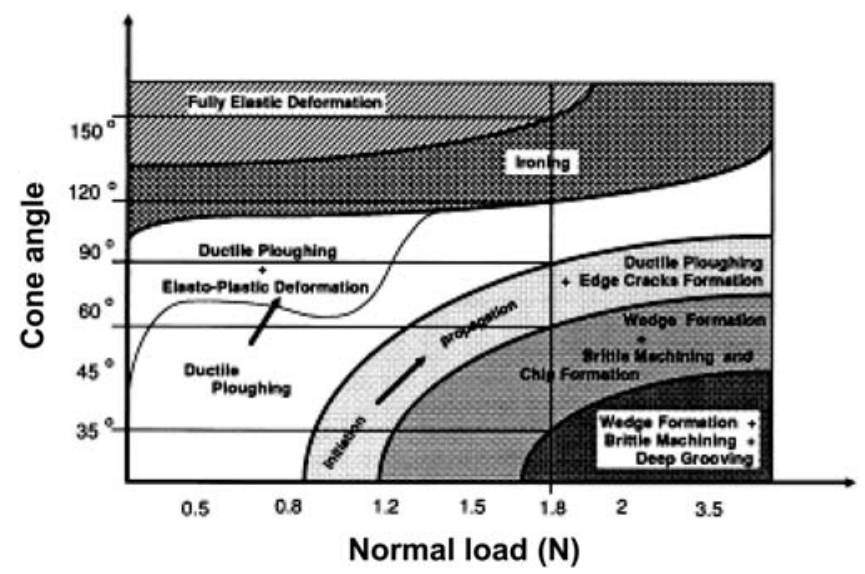

Fig. 3 Scratching map for poly(carbonate). The diagram shows results from scratching experiments performed at room temperature for a range of cone angles and normal loads and at a scratching velocity of $2.6 \mu \mathrm{m} \mathrm{s}^{-1}$ (from [25]) 
For a variety of glassy polymers, it is usually observed that cracks are induced at the leading edge of the contact under the action of predominantly tensile stresses, whose magnitude is assumed to be proportional to the frictional forces (Fig. 4). Accordingly, several authors have attempted to correlate this ductile-brittle transition to the tensile strength of the polymer material under investigation. Although some correlations emerge when parameters such as temperature, strain rate or indentation depth are considered [38-41], this analysis remains obscured by two factors. The first is connected to the difficulties in assessing the magnitude of the tensile stress field at the leading edge of the contact under largely viscoelastic/plastic conditions. A first order estimate can be obtained from well established elastic contact mechanics approaches (such as Goodman's theory [42], see below), but more precise calculations require the complexities of finite elements simulations which take into account strain hardening effects and viscoelastic recovery at the rear face of the indenter $[43,44]$.

Some difficulties also arise for the interpretation of scratch tests carried out at progressively increasing normal load or indentation depth. Figure 3 indicates, for example, that a transition from ductile deformation to brittle cracking can occur when increasing the normal load whilst the contact strain is nominally fixed by the conical indenter angle. This is indeed observed in many polymer systems and the notion of a critical load at the ductile-brittle transition is largely used to characterize the scratch response. This depth

(a)

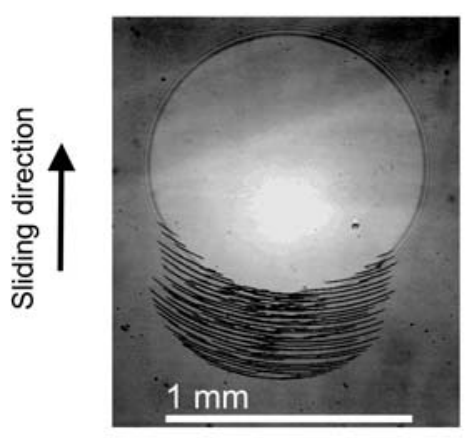

(b)

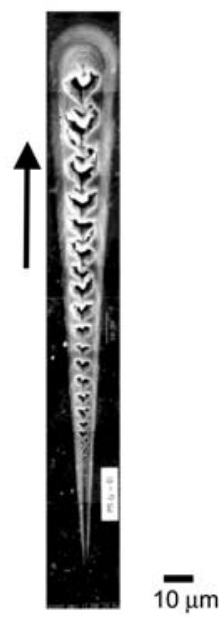

Fig. 4 Brittle failure modes of polystyrene within contacts. a Poly(styrene) film on a poly(methylmethacrylate) substrate. The regular crack pattern is induced by the sliding of a glass sphere under elastic contact conditions. b Poly(styrene) under viscoplastic scratching by a cone indenter (from [40]) 
dependence is usually interpreted by considering the enhancement of surface tensile stresses which may arise from some increase in the frictional forces at increased indentation depth, but some recent analysis by BertrandLambotte et al. $[45,46]$ indicates that some size effects could also be involved in the transition. According to an argument initially introduced by Puttick et al. $[47,48]$ for the analysis of the ductile-brittle transition during ball indentation of poly(methylmethacrylate), these authors suggested that the occurrence of brittle scratches can be interpreted using two different criteria. The first one is a fracture energy criterion which states that a crack of width $c$, subjected to a tensile stress, $\sigma_{\mathrm{t}}$, will grow if $\sigma_{\mathrm{t}}^{2} c / E \geq G_{\mathrm{c}}$, where $E$ and $G_{\mathrm{c}}$ are respectively the elastic modulus and the fracture energy. The second criterion is a size criterion which assumes that within a given volume, $a^{3}$, containing a crack of length, $c$, brittle failure will occur if the energy for crack propagation is less than that required for plastic deformation, i.e. $2 G_{\mathrm{c}} / \sigma_{\mathrm{y}} \varepsilon_{\mathrm{y}} \leq a$, where $\sigma_{\mathrm{y}}$ and $\varepsilon_{\mathrm{y}}$ are respectively the yield stress and plastic strain. According to Bertrand-Lambotte et al., the occurrence of brittle scratch, attributed by most authors to a critical load can be due to the fulfillment of either the fracture energy criterion or the size criterion. An estimate of the latter criterion for polymeric coatings reveals that the critical size at the ductile/brittle transition is of the order of a few micrometres, which corresponds to the characteristic scratch width at the onset of brittle propagation using pyramidal indenters.

\section{2}

\section{In Situ Contact Visualization Techniques}

When using transparent indenters and/or polymer materials, in situ contact visualization proved to be an efficient technique to investigate the dynamics of deformation and failure processes within sliding contacts. Such approaches have been recently developed within the context of scratch tests in order to investigate the elastic recovery of scratch grooves left on the surface of poly(methylmethacrylate) $[49,50]$ at the micrometre scale. They proved to be especially useful for analysing the transition from viscoplastic scratching to elastic sliding as a function of temperature, strain and strain rate.

The resources of in situ contact visualization have also recently been used to investigate crack initiation and propagation within brittle amorphous polymers under contact fatigue conditions. A detailed insight into the development of surface fatigue cracks was provided by means of specific tribological tests which rely upon the use of small-amplitude oscillating micromotions, often referred to as "fretting". In such a technique, a millimetresized macroscopic contact is typically formed between a polymer flat and a smooth spherical counterface under a constant applied normal force. This contact is submitted to lateral relative microdisplacements under cyclic conditions. As compared to other more conventional reciprocating sliding tests, 
the specificity here is that the magnitude of the imposed relative displacement (between about 1 and $100 \mu \mathrm{m}$ ) is much smaller than the size of the contact. In other words, this means that the contact area is nearly stationary with respect to the polymer surface, which considerably simplifies the analysis of crack development as compared to large amplitude sliding tests where multiple crack interactions have to be taken into account $[51,52]$.

Such an in situ visualization of fretting contacts demonstrated that it was possible to induce, at a length scale of millimetric, the development of a crack network without the unwanted complexities which could arise from the simultaneous development of an intercalating third body layer [53]. From the point of view of polymer fracture processes, this means that such fretting contacts may be viewed as some kind of model single-asperity contacts, which simulate, at an observable scale, contact fatigue processes. The use of this methodology to investigate some of the aspects of the structure/contact fracture properties relationships is addressed in the following sections.

\section{3}

\section{Contact Fatigue Behaviour of Epoxy Polymers}

\section{1}

\section{Contact Conditions Under Small Amplitude Micromotions}

The establishment of the interrelationships between polymer fracture properties and contact fatigue behaviour requires some knowledge of the contact stress field. The specificity of fretting loading is that, depending on the applied contact load and imposed relative displacement, two different contact conditions can be achieved within the interface [54,55] (Fig. 5):

(1) The so-called partial slip condition, where the contact area is divided into a central stuck zone and a surrounding annulus where some microslip is occurring during the course of the loading cycle. When the tangential load is plotted as a function of the relative displacement in a Lissajous representation, elliptical loops are obtained.

(2) A gross slip condition, where sliding is induced within the whole contact interface after a preliminary partial slip stage. This condition is associated to trapezoidal tangential load/displacement loops. The plateau value of the tangential load provides a measurement of the coefficient of friction, $\mu=Q^{*} / P$, where $Q^{*}$ and $P$ are the plateau value of the tangential load and the imposed normal load respectively.

The occurrence of either partial slip or gross slip condition is dependent on the material mechanical properties, the magnitude of the coefficient of friction and the contact loading parameters (normal load, imposed displacement). When dealing with non-adhesive elastic materials, the effects of these 

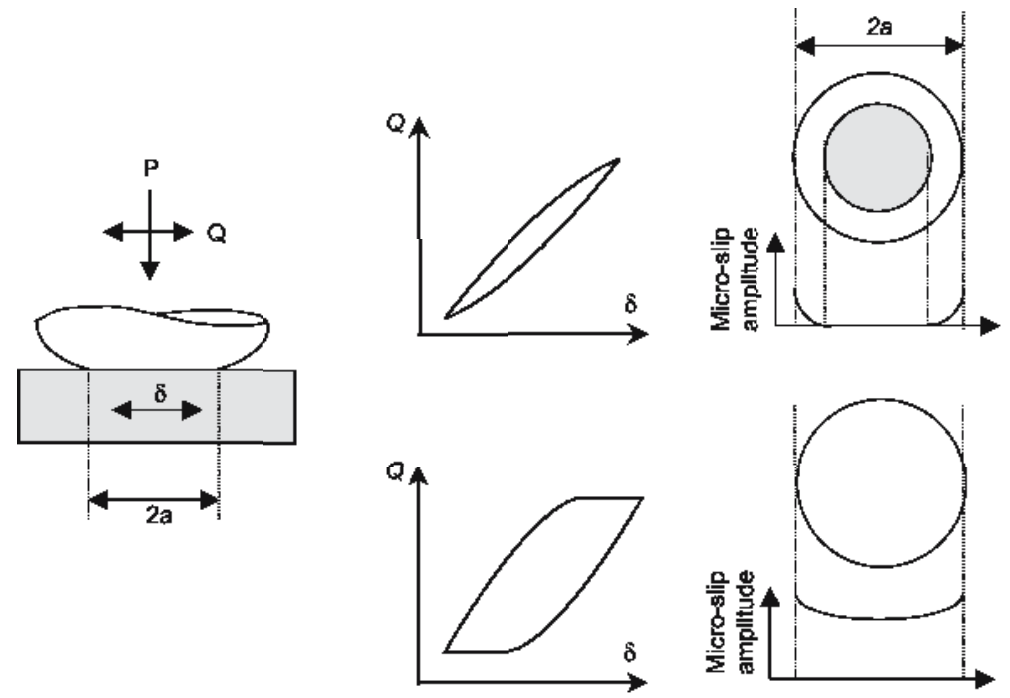

Fig. 5 Schematic description of the contact conditions encountered under small amplitude cyclic lateral micro-motions (fretting). $\delta$ is the applied lateral displacement, $Q$ is the lateral force and $P$ is the applied constant normal load. The elliptic and trapezoidal $Q(\delta)$ loops correspond to partial slip and gross slip condition respectively

factors can be rationalized by means of some conventional contact mechanics approach such as Mindlin's analysis [54]. This approach in particular provides the value of the critical displacement amplitude, $\delta_{\mathrm{t}}$, at the transition from partial slip to gross slip conditions:

$$
\delta_{\mathrm{t}}=\frac{K_{1} \mu P}{a}
$$

with

$$
K_{1}=\frac{3}{16}\left(\frac{2-v_{1}}{G_{1}}+\frac{2-v_{2}}{G_{2}}\right)
$$

where the subscripts 1 and 2 refers to the contacting bodies and $G$ and $v$ are respectively the shear modulus and the Poisson's coefficient.

With polymers, complications may potentially arise due to the material viscoelastic response. For glassy amorphous polymers tested far below their glass transition temperature, such viscoelastic effects were not found, however, to induce a significant departure from this theoretical prediction of the boundary between partial slip and gross slip conditions [56].

During the course of a cyclic test, some changes in the coefficient of friction may arise as a consequence, for example, of the development of physicochemical interactions between the contacting surfaces. For glass in contact with glassy polymers such as poly(methylmethacrylate) or epoxies, an in- 

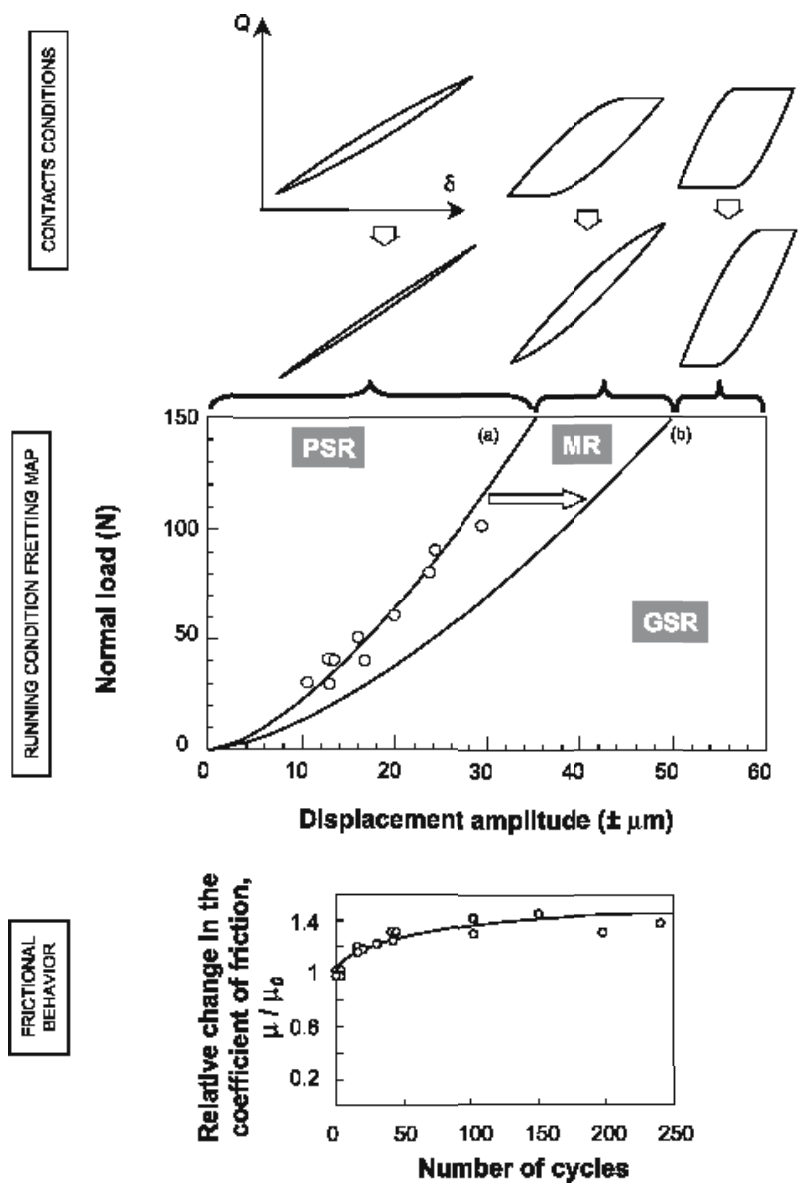

Fig. 6 Schematic description of fretting contact conditions as a function of displacement amplitude, normal load and number of loading cycles for a glass/epoxy contact (from [56]). PSR Partial slip regime, MR mixed regime, GSR gross slip regime. Solid lines in the running conditions fretting maps correspond to the theoretical boundary between partial slip and gross slip conditions, as calculated from Eq. 2 and using the initial (a) and steady-state (b) values of the coefficient of friction. Open symbols correspond to the experimental values of the initial boundary between partial slip and gross slip conditions. The relative increase in the measured coefficient of friction, $\mu$, as a function of the number of fretting cycles is reported in the lower figure ( $\mu_{0}$ is the initial value of the coefficient of friction). The resulting shift of the partial slip/gross slip boundary defines the mixed regime which is characterized by a change from gross slip to partial slip condition during the course of the fretting test

crease in the coefficient of friction is often observed during some preliminary running-in period, even in the absence of any observable contact damage. One of the effects of this time-dependent frictional behaviour is to induce a progressive transition from gross slip to partial slip conditions in some in- 
termediate displacement regime located close to the initial boundary between the partial slip and gross slip conditions.

As a conclusion, contact conditions under fretting loading can be classified into three different regimes: a partial slip regime, a gross slip regime and a mixed regime which is characterized by the progressive transition from gross slip to partial slip conditions during the course of the cyclic test. The occurrence of these various regimes can conveniently be synthesized as a function of the normal load and the imposed tangential displacement in the so-called running fretting condition maps [57, 58] (Fig. 6), where the boundaries between the various domains can be delimited by means of Eq. 1 . As detailed below, the identification of these various regimes is of primary importance to set up the boundary conditions for the contact mechanics modelling of the stress field induced by the cyclic loading. From the point of view of contact fatigue processes, the fretting maps also emphasize the fact that cracking processes are potentially induced under a non-constant amplitude fatigue loading, as opposed to current practice for bulk fatigue testing.

\section{2}

\section{In Situ Analysis of the Cracking Behaviour}

In this section, contact fatigue cracking mechanisms will be reviewed in the case of an epoxy network obtained by fully cross-linking a stoichiometric mixture of diglycidyl ether of bisphenol (DGEBA) and isophoron diamine (IPD). It was, however, observed that the nature of the various cracking processes remains fundamentally unchanged when various glassy epoxy networks differing in their chemical structure are considered; the main differences lies in crack initiation times and crack growth rates. The results described here for the DGEBA/IPD network can thus be considered a picture of generic contact fatigue processes within brittle epoxy networks tested in their glassy state.

A typical example of the development of a crack network within the gross slip regime is shown in Fig. 7. In addition to in situ visualization through the glass cap, the crack growth rates were also monitored by means of measurements of the contact lateral stiffness, $K$. As indicated in the insert in Fig. 7, this latter parameter corresponds to the slope of the $Q(\delta)$ relationship during the incipient stages of the tangential loading, i.e. in the limit of small relative displacements. Under such conditions, one can neglect the effects of partial slip and describe the tangential loading as the drag of a circular region of the sample surface by the slider. In the case of an elastic, uncracked body, the associated lateral stiffness is known to be proportional to the contact radius and the elastic modulus of the materials [54]. When a crack propagates in the contact zone, a significant drop in the measured contact stiffness can therefore be expected by virtue of 


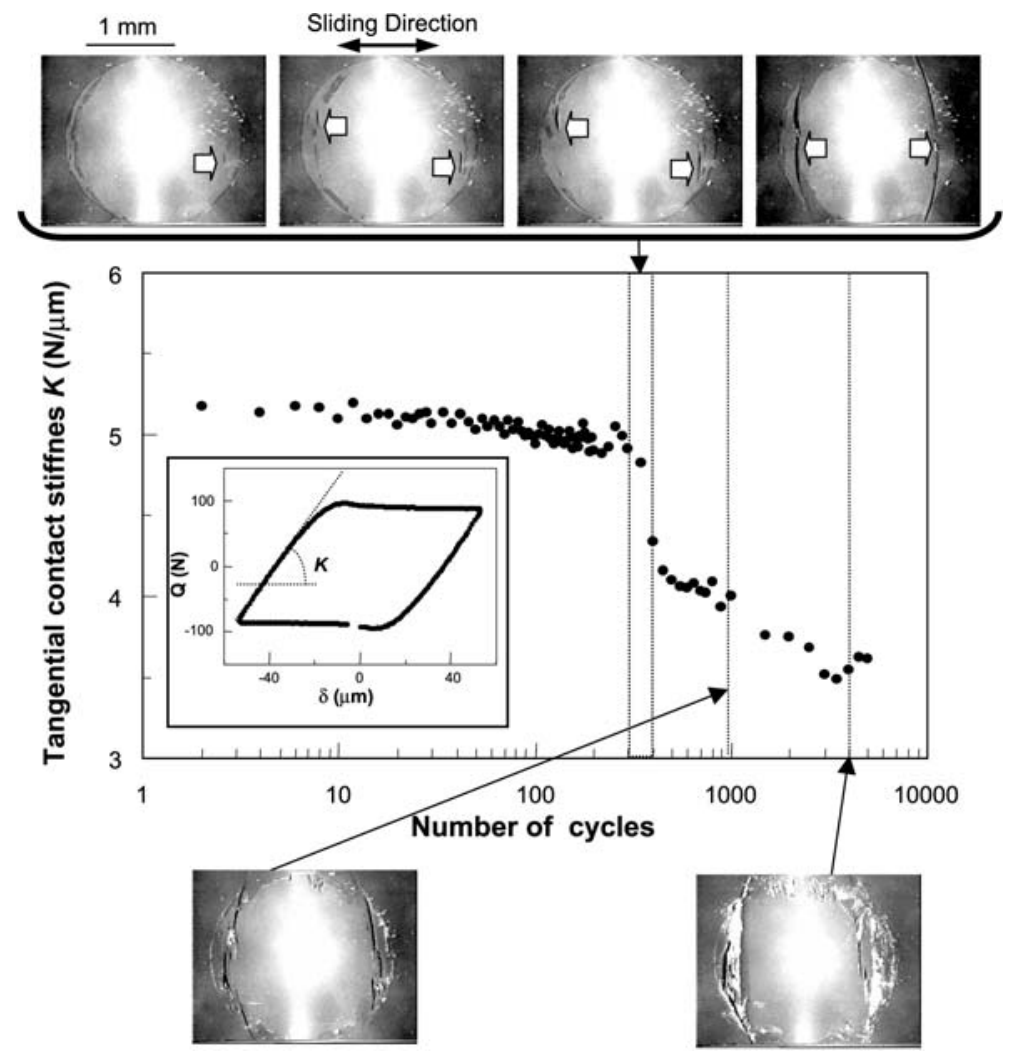

Fig. 7 Development of fatigue cracks in an epoxy/glass contact under gross slip condition ( $1 \mathrm{~Hz}$, displacement amplitude: $\pm 60 \mu \mathrm{m}$ ) (from [97]). White arrows indicate the occurrence of crack initiation and propagation at the edge of the contact under the action of tensile stresses. The lateral contact stiffness, $K$, is essentially a measurement of the elastic response of the epoxy substrate within the contact zone. Brittle crack propagation is associated to a drop in stiffness due to the additional accommodation of the imposed displacement provided by crack opening mechanisms

the reduction in the stiffness of the cracked body which results from crack opening mechanisms. As detailed below, this effect is particularly marked when the crack depth becomes of the order of magnitude of the contact radius.

Three successive stages can schematically be distinguished during the course of a contact fatigue test:

(1) A crack initiation stage which corresponds to the nucleation of two separate surface cracks close the edge of the contact and at two approximately symmetrical locations along the sliding direction. Within the resolution of the optical device (about $10 \mu \mathrm{m}$ ), crack nucleation was detected after about 300 loading cycles. During the next 100 fretting cycles, the cracks propagate in 
progressive, fatigue-like manner along a direction roughly perpendicular to the sliding direction.

(2) When some critical crack length (between $200 \mu \mathrm{m}$ and $400 \mu \mathrm{m}$, i.e. about $15 \%$ of the contact diameter) is reached, a brittle propagation stage is observed which is associated with a sudden and drastic drop in the lateral stiffness, $K$. The measured crack width in the plane of the contact is then of the order of magnitude of the contact diameter. Post-mortem microscope observation of specimen cross sections in the contact zone (Fig. 8) indicates that the depth of the cracks is of the order of magnitude of the contact radius (i.e. about $900 \mu \mathrm{m}$ ). The two deep cracks induced at the edge of the contact may thus be viewed as some kind of "half-penny" cracks whose radii are approximately equal to the radius of the contact. In the subsequent part of this paper, the two deep cracks will be referred to as "primary cracks".

(3) After the brittle propagation stage, "secondary cracks" are subsequently induced in the vicinity of the two primary cracks, but they result in a more limited and progressive decrease in the contact stiffness. Observation of contact cross-section shows that the depth of these cracks is strongly reduced compared to those of the primary cracks. After the propagation of the primary cracks, stresses are relaxed in their vicinity as a consequence of crack opening mechanisms, which can account for the limited propagation of the secondary cracks.

A simple contact mechanics analysis shows that the observed crack network at the vicinity of the contact edge is essentially induced under the action of alternate tensile and compressive stresses oriented along the sliding direction. According to acknowledged analytical expressions for the stress field induced by a sliding sphere on an elastic substrate [42], it appears that the complex multiaxial contact stress field reduces to a predominantly tensile/compressive loading in the region where crack nucleation is experimentally detected. An estimate of the maximum value of the tensile stress, $\sigma_{\mathrm{xx}}^{\max }$, experienced at the trailing edge of the contact is provided by the follow-

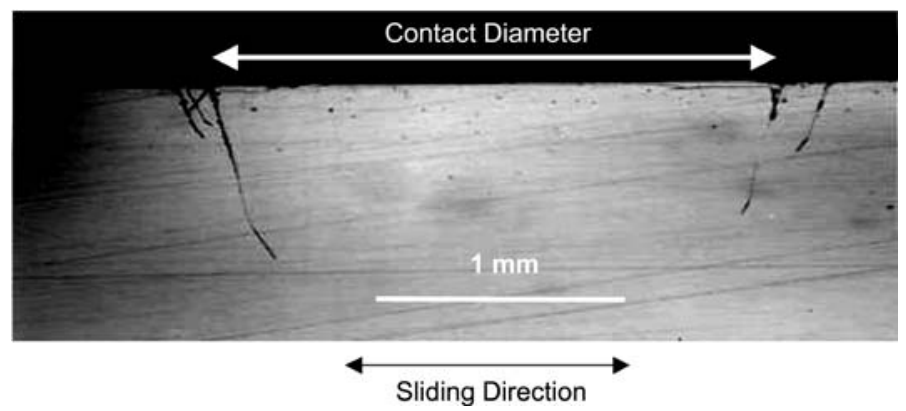

Fig. 8 Post mortem optical observation of a contact cross-section showing crack depth and orientation within an epoxy polymer after contact fatigue 
ing formula:

$$
\sigma_{\mathrm{xx}}^{\max }=\frac{3 P}{2 \pi a^{2}}\left[\frac{1-2 v}{3}+\frac{4+v}{8} \pi \mu\right] \text {. }
$$

Where $P$ is the applied normal load, $a$ is the contact radius, $v$ is the Poisson's ratio and $\mu$ is the coefficient of friction. For the above-described experiments,

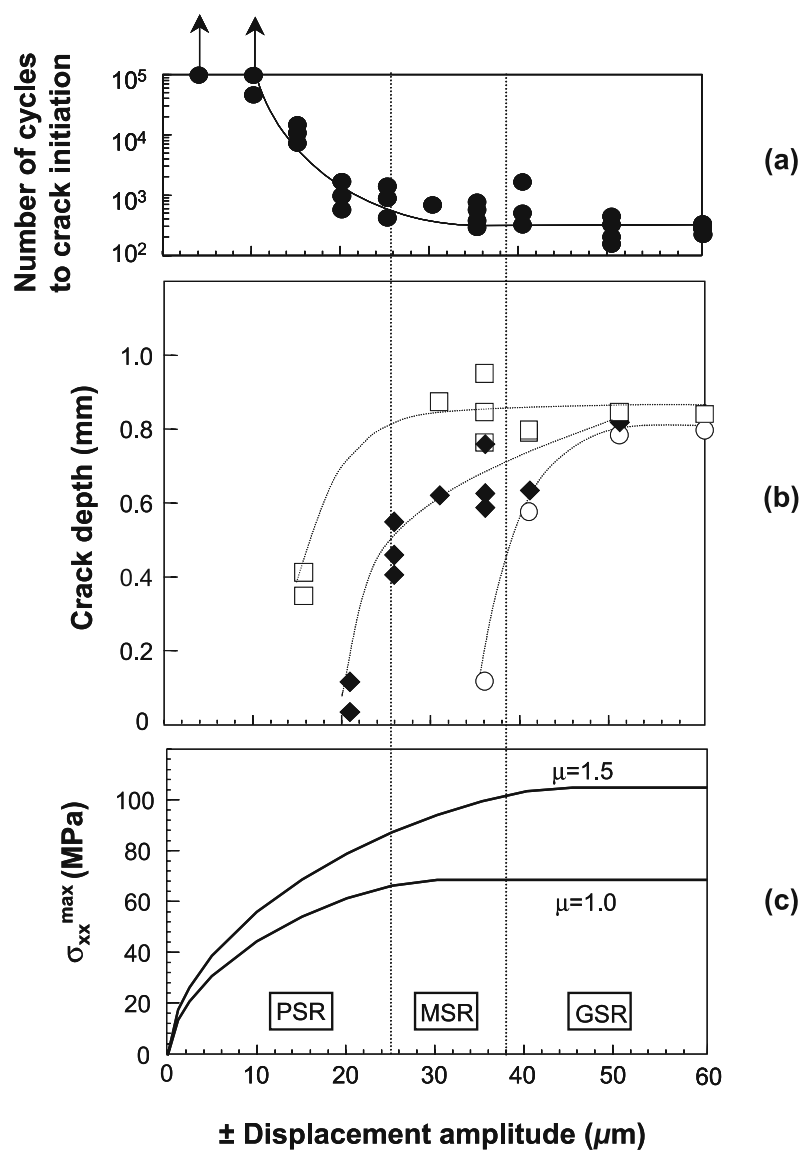

Fig. 9 Changes in the crack initiation times and crack depths in an epoxy resin as a function of the amplitude of the imposed cyclic displacement. a Number of cycles to the initiation of the primary cracks at the edge of the contact zone. b Measured depths of the primary cracks at various number of cycles and displacement amplitudes. Circles $10^{3}$ cycles, solid diamonds $5 \times 10^{3}$ cycles, squares $5 \times 10^{4}$ cycles. c Calculated values of the maximum tensile stress at the edge of the contact using Hamilton (gross slip condition) or Mindlin-Cattaneo (partial slip condition) theories. The two curves correspond to calculations using the initial $(\mu=1.0)$ and the steady-state $(\mu=1.5)$ values of the coefficient of friction. PSR Partial slip regime, MR mixed regime, GSR gross slip regime 
the calculated values of $\sigma_{\mathrm{xx}}^{\max }$, are in the range 50-100 MPa depending on the value of the coefficient of friction, which is consistent with the development of fatigue/brittle failure processes.

The characteristic features of the crack network remain essentially unchanged within the partial slip and mixed regimes: primary and secondary cracks are successively induced at the edge of the contact but, as opposed to the gross slip regime, both the number of cycles to crack initiation and the crack growth rates appear to be strongly sensitive to the magnitude of the applied relative displacement (Fig. 9). The more the imposed displacement is reduced, the more crack initiation processes are delayed. For approximately $\pm 10 \mu \mathrm{m}$, a contact endurance limit can be identified below which no crack is nucleated after $10^{5}$ cycles. In addition to these increased crack nucleation times, the measured crack depths (i.e. perpendicular to the contact plane, Fig. 9) and crack lengths (i.e. in the contact plane, Fig. 10) are strongly reduced at low displacement amplitudes (Fig. 10). Within the partial slip regime, it is also no longer possible to detect any brittle failure event as it is the case in the mixed and gross slip regimes (Fig. 10).

Under partial slip conditions, the estimate of the stress conditions at the edge of the contacts is complicated due to the unknown frictional behaviour within the partial slip annulus. If Coulomb's friction law is assumed to apply locally within this area, some contact mechanics calculation can, however, be

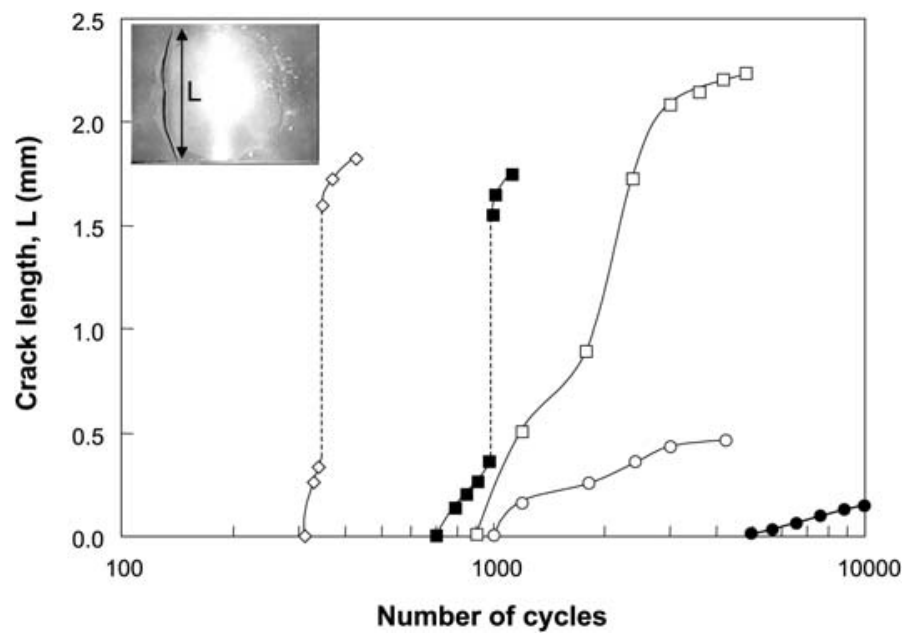

Fig. 10 Measured crack lengths, $L$, in an epoxy polymer as a function of the number of cycles and the imposed lateral displacement. The crack length was measured in the contact plane from in situ observations. Amplitude of the relative displacement: Black circles $\pm 15 \mu \mathrm{m}$, white circles $\pm 20 \mu \mathrm{m}$, white squares $\pm 25 \mu \mathrm{m}$, black squares $\pm 30 \mu \mathrm{m}$, white diamonds $\pm 60 \mu \mathrm{m}$. Dotted lines indicate the occurrence of brittle failure events during the course of the contact fatigue experiments 
carried out using conventional Mindlin-Cattaneo [54,59] approaches. Such calculations show that the tensile/compressive nature of the stress field at the edge of the contact remains essentially unchanged as the amplitude of the displacement is decreased within the partial slip regime. As shown in Fig. 9, a significant decrease in the magnitude of the maximum value of the tensile stress is also predicted when the displacement amplitude is reduced, which can account for the observed reduction in the extent of the contact cracking processes.

\section{3}

\section{Crack Initiation: The Relevance of Bulk Fatigue Properties}

The fact that contact cracks are induced under a predominantly uniaxial tensile loading makes it realistic to attempt to establish some relationships with bulk fatigue behaviour under tensile conditions. Fatigue data for neat epoxy resins are scarce in the literature, but tend to indicate that, for unnotched specimens, most of the fatigue life is often consumed during crack initiation processes which take place close to the specimen surface $[60,61]$. Such an observation is consistent with the above-described contact fatigue behaviour, especially in the mixed and gross slip regimes, where it was observed that crack initiation was rapidly followed by some brittle failure events.

When crack initiation is considered, some questions arise regarding the potential dependence of such processes on the stressed polymer volume, which largely differs between bulk fatigue testing and contact fatigue (in the latter case, the stressed volume is of the order of magnitude of the cube of the contact radius, i.e. a few $\mathrm{mm}^{3}$ ). Such volume effects could be very significant in situations where crack initiation involves randomly distributed pre-existing flaws such as voids or inclusions. The mechanisms for crack initiation in amorphous polymers such as epoxies are still largely unclear, but they do not seem to involve any detectable pre-existing flaws, voids or inclusions $[60,61]$. Observations of fracture surfaces show that fatigue cracks are usually nucleated on the specimen surface after a period which is close to the time to fracture. Nagasawa et al. [60] have also made the interesting observation that if a specimen is allowed to rest overnight when the fatigue test has proceeded by about $80 \%$ of the expected number of cycles to failure, the fatigue life of the specimen is subsequently increased by the corresponding number of fatigue cycles. Moreover, if such resting periods are alternated with successive fatigue cycling sequences, there is some indication that the fatigue life is considerably increased. These observations were tentatively interpreted by Nagasawa et al as showing that crack initiation is associated with some kind of recoverable strain accumulation close to the specimen surface. In an early work, Rabinowitz and co-workers [62] also showed that crack nucleation during fatigue testing of amorphous polymers such as polycarbonate is preceded by some strain-activated changes in the cyclic stress-strain re- 
sponse (cyclic strain softening) which were assumed to involve the nucleation and growth of microscopic defects within the glassy polymer. All these observations tend to support the idea that the relevant length scale for crack nucleation processes lies in the microscopic range, probably even at some molecular level. This means that no significant dependence of crack initiation on the stressed volume is likely to occur and that the use of bulk fatigue data should be relevant in the context of contact crack initiation.

More importantly, the hypothesis of crack nucleation processes involving some strain or molecular defects accumulation within the polymer addresses the question of the elastic or plastic nature of the deformation at the crack initiation location. By virtue of the strong heterogeneities of the contact loading, some localized plasticity may occur even if the contact remains, as a whole, loaded elastically. The occurrence of plastic deformation in the contact zone can be analysed using some multiaxial plasticity criteria. When considering the use of such criteria for polymers, some care must be taken, regarding the well known effects of hydrostatic pressure on the yield behaviour of glassy polymers. Owing to the confinement of the polymer material within the contact zone, such effects are likely to be significant and some modified form of conventional yield criteria have to be considered. In the case of epoxy materials subjected to a multiaxial stress field under constrained states of stress Lesser et al. $[63,64]$ demonstrated the validity of a modified Von Mises criterion which can be expressed as a function of the octahedral shear stress, $\tau_{\mathrm{y}}^{\mathrm{oct}}$ :

$$
\tau_{\mathrm{y}}^{\mathrm{oct}}=\tau_{\mathrm{y} 0}^{\mathrm{oct}}-\alpha \sigma_{\mathrm{H}}
$$

where $\sigma_{\mathrm{H}}$ is the hydrostatic stress and $\tau_{\mathrm{y} 0}^{\mathrm{oct}}$ is the octahedral shear yield stress in the absence of $\sigma_{\mathrm{H}} \cdot \alpha$ is a coefficient that quantifies the hydrostatic pressure dependence of the yield limit. The octahedral shear stress, $\tau^{\text {oct }}$ and $\sigma_{\mathrm{H}}$ can be expressed as a function of the principal stresses as follows:

$$
\begin{aligned}
\tau^{\text {oct }} & =\frac{1}{3}\left[\left(\sigma_{1}-\sigma_{2}\right)^{2}+\left(\sigma_{1}-\sigma_{3}\right)^{2}+\left(\sigma_{2}-\sigma_{3}\right)^{2} 1 / 2\right. \\
\sigma_{\mathrm{H}} & =-\frac{1}{3}\left(\sigma_{1}+\sigma_{2}+\sigma_{3}\right)
\end{aligned}
$$

Under gross slip conditions, the distribution of octahedral shear stress and pressure within the contact can be calculated from the explicit theoretical expressions of the contact stresses beneath a rigid sliding sphere which were derived by Hamilton [42]. As detailed in $[63,65]$, the two parameters, $\tau_{\text {octo }}$ and $\alpha$ can be obtained from an appropriate combination of bulk mechanical tests such as uniaxial and plane strain compression tests. For practical reasons, the equivalent strain rates used during the bulk mechanical testing are usually lower than the strain rates achieved within the epoxy surface layer during contact fatigue (of the order of $10^{-2} \mathrm{~s}^{-1}$ at $1 \mathrm{~Hz}$ ). Accordingly, the values of the octahedral shear stress at the onset of yield are probably slightly 
underestimated, although the strain rate dependence in the glassy state is not likely to be very important well below the glass transition temperature.

As an example, a calculated octahedral shear stress profile is reported in Fig. 11 that corresponds to the surface of the epoxy specimen, where the maximum value of the octahedral shear stress is likely to occur. This figure indicates that the contact remains elastic for the contact conditions under investigation, except within a narrow region located at the edge of the contact, which corresponds to the observed crack initiation sites. Such a contact mechanics analysis therefore supports the hypothesis of a potential activation of crack nucleation processes by some localized plastic strain accumulation at the edge of the contact, as a result of the strong strain localization associated with the tangential loading.

A quantitative analysis of contact crack nucleation processes typically involves the following ingredients:

(1) A multiaxial analysis of the cyclic stresses experienced by the material in the vicinity of the crack initiation sites. On the basis of a contact mechanics analysis, the amplitude of the average tensile and shear stresses is calculated along the initial crack direction in order to identify the nature and the level of the local stress field associated to crack initiation.

(2) an estimate of the fatigue properties of the bulk material under loading conditions which are representative of that induced in the initial crack direction. Such a condition is not always easy to fulfill in situations where crack

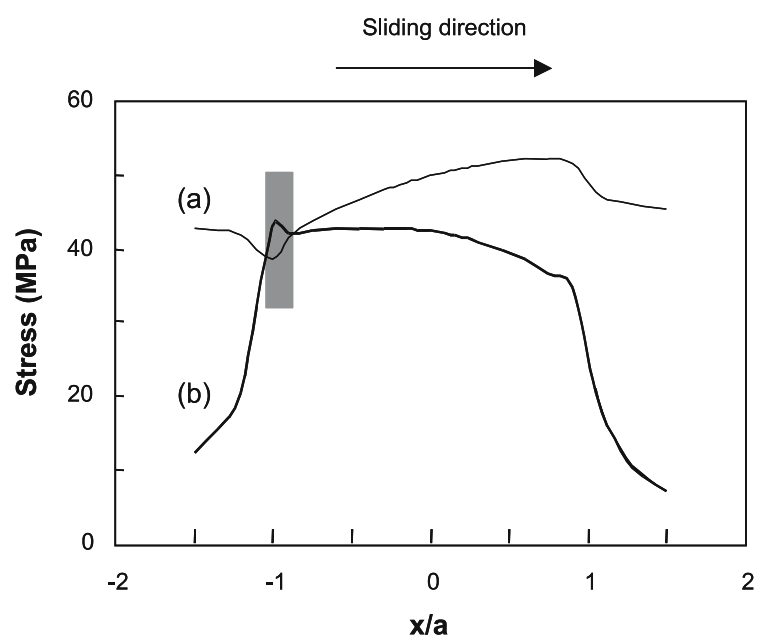

Fig. 11 Calculated surface profiles of the octahedral shear stress at yield assuming a modified Von Mises criterion $(a)$, and of the octahedral shear stress for a glass/epoxy contact under gross sliding condition $(b)$. The grey area delimits the region at the leading edge of the contact where the octahedral shear stress is exceeding the limit octahedral shear stress at yield ( $a$ is the radius of the contact area) (from [97]) 
initiation involves a complex multiaxial stress field. However, the analysis detailed below shows that the cracks initiated at the edge of the contacts are induced under predominantly tensile conditions, which facilitates the comparison to the bulk tensile fatigue response.

For elastic materials, the contact problem is usually solved as a unilateral contact problem obeying Coulomb's friction law. The algorithms used here are based on those pioneered by Kalker [66]. The contact area, the stick and slip regions, the pressure and traction distributions are numerically determined first and then the stress and displacement distributions within the elastic bodies can be established at the various stages of the tangential cyclic loading. On the basis of these calculations, the occurrence of crack initiation processes can subsequently be analysed in the meridian plane of the contact, $y=0$ (Fig. 12), where the cracks first initiate. As a first approach, parameters based on the amplitude of the shear stress, $\tau_{\mathrm{m}}$, along a particular direction and the amplitude of the tensile stress, $\sigma_{\mathrm{m}}$, perpendicular to this direction,

\section{Three dimensional contact analysis}
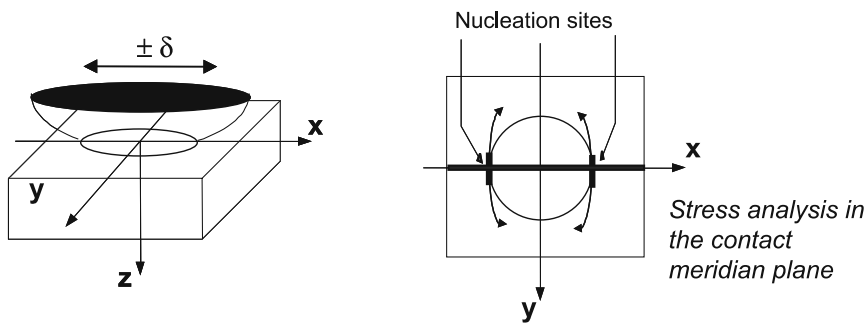

Theoretical approach to initial crack growth

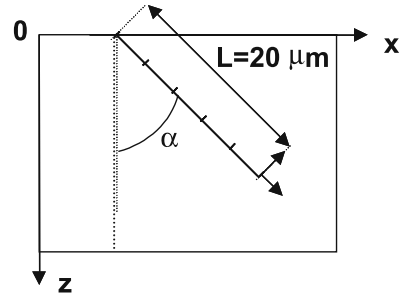

$$
\begin{gathered}
\tau_{m}=\frac{1}{n_{p}} \sum_{1}^{n_{p}} \sigma_{n t} \\
\sigma_{m}=\frac{1}{n_{p}} \sum_{1}^{n_{p}} \sigma_{n n}
\end{gathered}
$$$$
\text { Average shear }
$$$$
\text { stress }
$$

Average tensile

stress

Fig. 12 Theoretical analysis of initial crack growth directions. In a first step, the threedimensional elastic contact stress field is calculated within the polymer body under small amplitude reciprocating micro-motions. A two-dimensional analysis of crack initiation is subsequently carried out using the calculated stress values in the meridian plane of the contact $(O x z)$. Average shear $\left(\tau_{\mathrm{m}}\right)$ and tensile $\left(\sigma_{\mathrm{m}}\right)$ stresses are calculated for different locations in the contact and for different orientations, $\alpha$, with respect to the normal to the contact plane 
can been considered to derive the crack initiation criterion [65]. These mechanical parameters essentially allow discrimination between predominant shear or tensile crack initiation driving forces.

For various discrete steps of the cyclic tangential loading, values of $\tau_{\mathrm{m}}$ and $\sigma_{\mathrm{m}}$ can be calculated for different orientations, $\alpha$, with respect to the normal to the surface and for different locations within the meridian plane. As an example, for an epoxy specimen under gross slip conditions, the maximum value, $\Delta \sigma_{\mathrm{m}}^{*}$, of the effective (i.e. $\sigma_{\mathrm{m}}>0$ ) amplitude of the average tensile stress on the surface $(z=0)$ has been reported as a function of the orientation in Fig. 13. In the same figure, the orientation, $\alpha^{*}$, of the plane corresponding to the maximum amplitude of the effective average tensile stress has also been reported. Owing to the loading symmetry and for the sake of clarity, only the results corresponding to one half of the contact have been represented. The results show that the maximum amplitude of $\sigma_{\mathrm{m}}$ occurs at the edge of the contact (i.e. $x / a=-1$ ) and along an orientation, $\alpha^{*}=7^{\circ}$, which is very close to the experimental initial crack propagation direction $\left(11^{\circ}\right)$. The calculations also reveal that, at the edge of the contact, the maximum amplitude of the shear stress, $\Delta \tau_{\mathrm{m}}^{*}$, is minimized along a direction corresponding to the maximum tensile stress amplitude (Fig. 14). In order to take into account the strong stress gradient close to the contact interface, $\tau_{\mathrm{m}}$ and $\sigma_{\mathrm{m}}$ had to be averaged over a finite length from the polymer surface. The calculated value of $\alpha^{*}$ was, however, found to be roughly independent of the depth up to $50 \mu \mathrm{m}$, while the amplitude of $\Delta \sigma_{\mathrm{m}}^{*}$ decreased only from $70 \mathrm{MPa}$ to $60 \mathrm{MPa}$ within the same range.

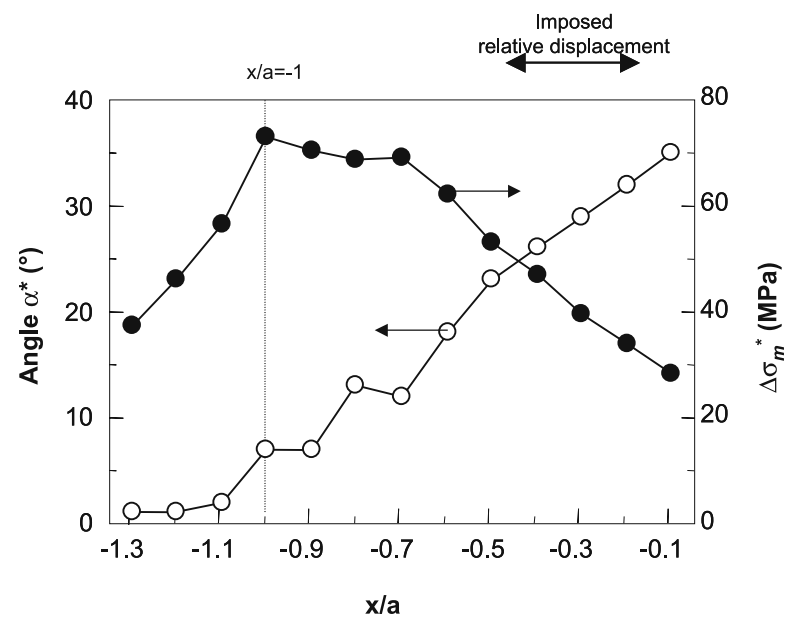

Fig. 13 Calculated amplitude $\left(\Delta \sigma_{\mathrm{m}}^{*}\right)$ and orientation $\left(\alpha^{*}\right)$ of the effective average tensile stress in an epoxy polymer as a function of the location within the contact area (gross slip condition, $a$ is the radius of the contact area, and the amplitude of the relative displacement is indicated by the double arrow) (from [97]) 


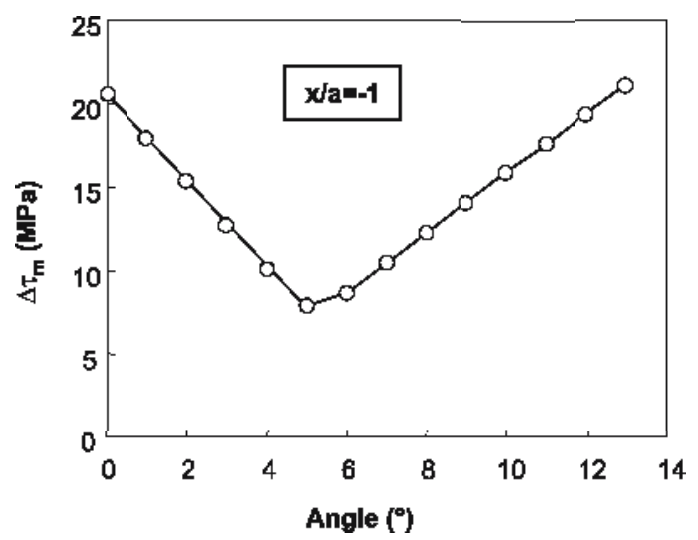

Fig. 14 Calculated values of the maximum shear stress amplitude, $\Delta \tau_{\mathrm{m}}^{*}$, at the edge of the contact $(x / a=-1)$ as a function of the orientation with respect to the normal to the surface (gross slip condition, $a$ is the radius of the contact area) (from [97])

This combined analysis of $\Delta \sigma_{\mathrm{m}}^{*}$ and $\Delta \tau_{\mathrm{m}}^{*}$ therefore establishes that the main cracks that nucleate close to the contact edge correspond to predominantly tensile fatigue cracks. This conclusion remains valid whatever the contact condition (partial slip or gross slip). In addition, the distribution of $\Delta \sigma_{\mathrm{m}}^{*}$ within the contact plane is of interest (Fig. 15). The maximum amplitude

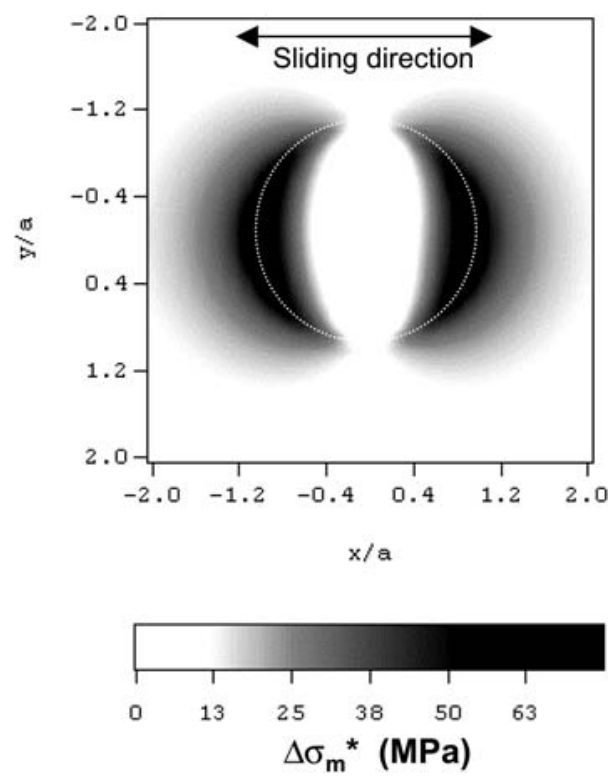

Fig. 15 Calculated distribution of the amplitude of the effective average tensile stress, $\sigma_{\mathrm{m}}^{*}$, within the plane of an epoxy glass contact under gross slip condition 
of the tensile stresses is located within two croissant-shaped areas oriented perpendicular to the sliding direction, which correspond closely to the regions where crack initiation was observed experimentally.

The calculated maximum tensile stress amplitude within the contact is of interest in the light of the bulk fatigue data of the DGEBA/IPD network. The latter were obtained under three-point bending conditions and it was verified from observations of the fracture surfaces that cracks nucleated and propagated on the tensile side of the specimen according to a mode I opening mechanism, similar in nature to that involved in contact fatigue. When the calculated value of the tensile stress amplitude at the edge of the contact (i.e. $\Delta \sigma_{\mathrm{m}}^{*}=70 \mathrm{MPa}$ ) under gross slip conditions is reported within the corresponding $S-N$ diagram, a fatigue life of about 250 cycles is obtained which corresponds closely to the experimental number of cycles to crack initiation under contact fatigue conditions (Fig. 16). It is worth noting that this good agreement between bulk and contact fatigues behaviours is observed despite the fact that the loading frequencies $(10 \mathrm{~Hz}$ and $1 \mathrm{~Hz}$ for bulk and contact fatigue, respectively) and the strain ratio $R=\varepsilon_{\min } / \varepsilon_{\max }$ ( 0.1 and -1.4 for bulk and contact fatigues respectively) are significantly different. Using the same approach, the tensile stress amplitude, $\Delta \sigma_{\mathrm{m}}^{*}$, can be calculated under partial slip conditions for a displacement amplitude which corresponds to the threshold of crack initiation. The calculated stress values are consistent with the experimental bulk endurance properties of the epoxy material, which fur-

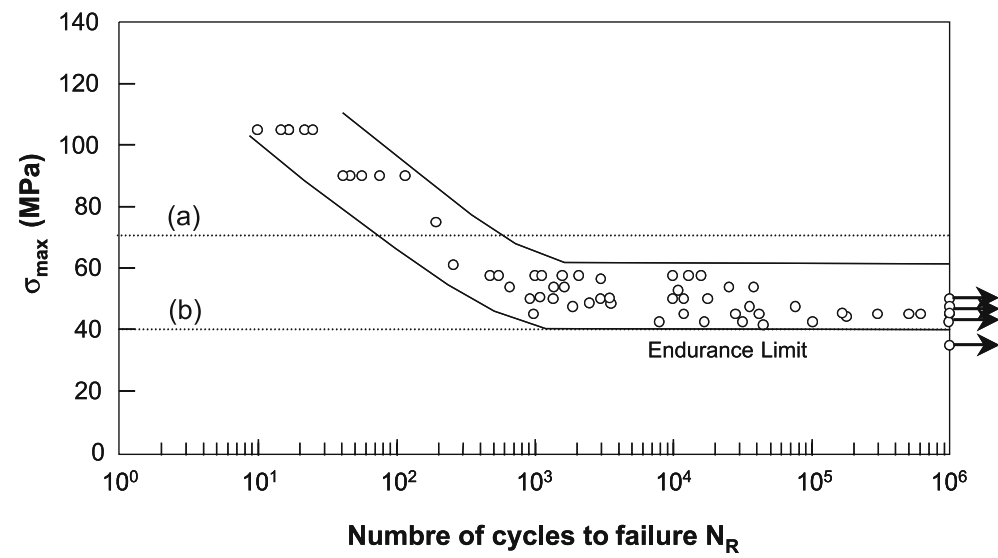

Fig. 16 S-N fatigue diagram of a bulk diglycidyl ether of bisphenol (DGEBA)/isophoron diamine (IPD) epoxy polymer giving the maximum applied stress as a function of the number of cycles to failure (three-point bending, $25 \mathrm{~Hz}$, stress ratio $\sigma_{\min } / \sigma_{\max }=0.1$ ) (from [53]). The two dotted lines correspond to theoretical values of the amplitude of the effective tensile stress, $\Delta \sigma_{\mathrm{m}}^{*}$, calculated for (a) gross slip condition and (b) under partial slip condition for an imposed displacement $( \pm 10 \mu \mathrm{m})$ which corresponds to the experimental contact endurance limit at $10^{5}$ cycles 
ther supports the relevance of bulk fatigue data within the context of contact fatigue behaviour of brittle epoxy materials.

\section{4}

\section{Crack Propagation: Ductile-to-Brittle Transitions}

The above-described contact mechanics analysis provides a good estimate of the initial crack orientation within the epoxy substrate. The problem of crack orientation is especially relevant in the context of fatigue wear processes because particle detachment is often considered to result from pitting mechanisms associated with the coalescence of adjacent cracks which propagate along different (declined) directions depending on the sliding direction and crack interaction. In such a situation, the wear rate can be assumed to be primarily dependent upon both the crack orientation and crack growth rate.

There is a long history behind the problem of crack propagation within contacts involving brittle materials, starting with the initial studies of Hertz on conical fractures at elastic contacts between curved glass substrates. As detailed in the book by Lawn [67], many of these investigations were in fact motivated by the wide use of indentation fracture as a simple microprobe for determining brittle material fracture parameters such as toughness, crack velocity exponent, etc. Key elements of the related contact problem are stress field inhomogeneity and crack stability, which often result in a breakdown of critical stress concepts to describe the threshold condition for the unstable propagation of cracks. These aspects have been addressed in particular within the context of indentation cracking of brittle material with pre-existing surface flaw distribution. From a combination of an Hertzian contact stress analysis with well known linear elastic fracture mechanics solutions for line cracks, it is possible to derive the values of the stress intensity factors along the trajectories of the Hertzian cones which are often observed under sphere indentation conditions. As an example, the results of such a calculation are reported in Fig. 17, where the stress intensity factors at the crack tip have been normalized with respect to the fracture toughness. Starting from an initial flaw size, $c_{\mathrm{f}}$, this curve shows that stable (i.e. $\mathrm{d} K / \mathrm{d} c<0$, where $c$ is the crack length) and unstable (i.e. $\mathrm{d} K / \mathrm{d} c>0$ ) propagation stages can successively be involved in indentation fracture when the normal load is increased. This approach highlights that the critical load at the threshold for unstable crack propagation is independent on the initial flaw size, but that it is determined by a critical crack depth, $\boldsymbol{c}_{\mathrm{c}}$, which is achieved after an initial stable propagation stage.

It is worth noting that this calculation of the stress intensity factor does not take into account the modification of the elastic stress field which results from crack propagation. However, the contact stiffness measurements carried out during contact fatigue of epoxy materials (see Fig. 7) show that a substantial change in the magnitude of the tangential loading and in the associated stress 

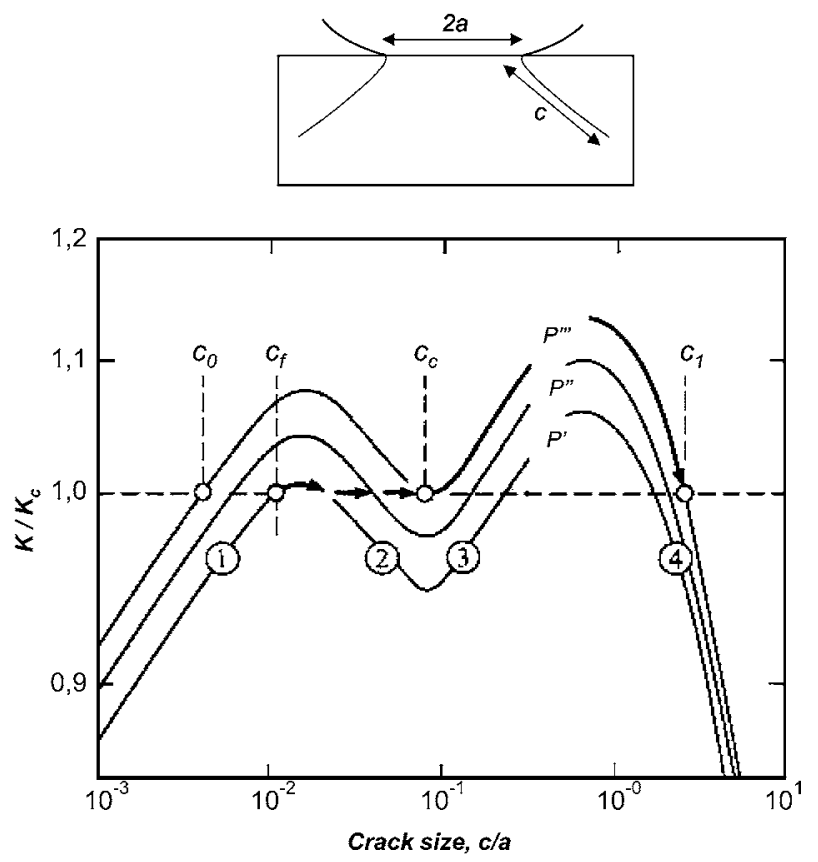

Fig. 17 Contact mechanics analysis of Herztian cracks within brittle materials.a Schematic description of a Hertzian cone crack induced under normal indentation by a rigid sphere. b Reduced plot of $K$-field as function of cone crack length and for increasing loads $P^{\prime}<P^{\prime \prime}<P^{\prime \prime \prime}$ during sphere-on-flat normal indentation of brittle materials. Arrowed segments denote stage of stable ring crack extension from $c_{\mathrm{f}}$ to $c_{\mathrm{c}}$ (initiation), then unstable to $c_{1}$ at $P=P^{\prime \prime \prime}$ (cone-crack pop-in) (From [67]). Branches (1) and (3) correspond to unstable crack propagation $(\mathrm{d} K / \mathrm{d} c>0)$, branches $(2)$ and (4) to stable crack propagation $(\mathrm{d} K / \mathrm{d} c<0)$

field can occur when the crack length become of the order of magnitude of the contact radius.

Thus, more recently, refined fracture mechanics approaches have been developed which take into account the modifications of the elastic stress field associated with crack propagation as well as the effects of potential microsliding mechanisms between the crack faces [68-70]. Without going into detail, stress and displacement fields are obtained by superimposing the individual responses of the uncracked solid and of the cracks to the contact loading in a manner that satisfies the boundary conditions along the faces of the cracks The crack response is associated with displacement discontinuities along its faces (opening and slip processes) which generate stresses.

Such approaches have been applied to the contact cracking problems under sliding conditions in order to assess the values of the stress intensity factors $K_{\mathrm{I}}$ and $K_{\mathrm{II}}$ under cyclic tangential loading. As an example, Fig. 18 shows the numerical simulations corresponding to a cracked epoxy substrate. 

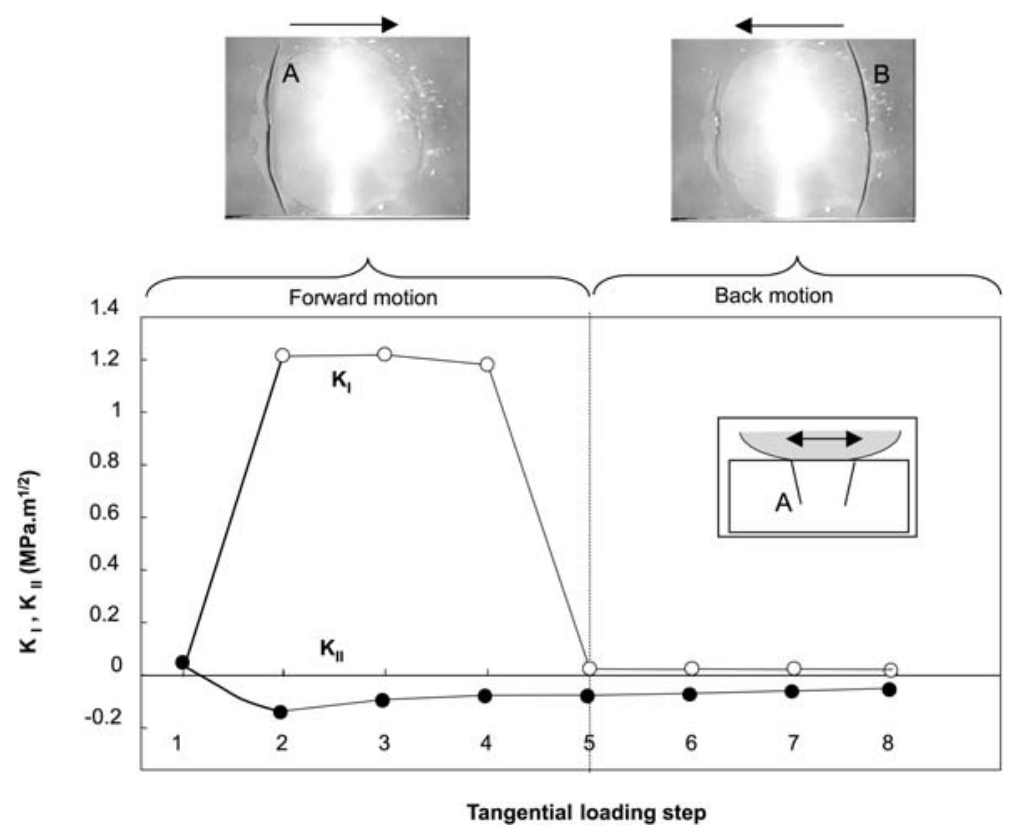

Fig. 18 Calculated values of the mode I $\left(K_{\mathrm{I}}\right)$ and mode II $\left(K_{\mathrm{II}}\right)$ stress intensity factors within a cracked epoxy at various stages of a cyclic contact loading. Two cracks $350 \mu \mathrm{m}$ in length and oriented at $10^{\circ}$ with respect to the normal to the epoxy surface have been considered. For symmetry reasons, only the results corresponding to one crack (denoted A) have been represented. The tangential cyclic loading has been divided into eight successive steps

The crack behaviour and the associated stress intensity factors during the various discrete steps of the cyclic tangential loading are represented. During the alternate tangential loading, opening (steps 1 to 4 ) and closing (steps 5 to 8) mechanisms of the crack were simulated in accordance with the in situ observation of the crack dynamics. This calculation of $K_{\mathrm{I}}$ and $K_{\mathrm{II}}$ also clearly demonstrates the complex non-proportional nature of the loading at the crack tip. It is usually found, however, that for such cracks the magnitude of $K_{\mathrm{II}}$ is much less than that of $K_{\mathrm{I}}$, which means that the tip loading is essentially of a mode I nature.

When considering the use of such a fracture mechanics analysis to analyse the propagation of relatively short cracks within epoxy, some complications could arise from the potential formation and breakdown of crazes. Although the existence of crazes in epoxies has been the matter of some debate, there appears to be overwhelming evidence against the occurrence of such failure mechanisms in bulk specimens of these polymers [71]. Investigation of mode I failure mechanisms in epoxy resins also invariably indicates that, depending on the temperature, the loading rate and the yield properties, two distinct 
type of propagation mode can be encountered, namely a stable (continuous) propagation or an unstable "stick-slip" mode [71-73]. The unstable crackgrowth behaviour is generally attributed to localized crack tip yielding [73]. Accordingly, the fracture energies for crack initiation increase with increasing temperatures (or decreasing loading rates) due to the temperature and strain rate dependence of the yield stress. On the other hand, fracture energies for crack arrest were nearly independent of temperature and were similar to the fracture energies for stable propagation. The yield stress therefore appears to be the controlling parameter regarding the nature of crack propagation (Fig. 19). During the course of contact fatigue experiments, in situ observations indicated that the brittle propagation stages observed within the mixed and gross slip regimes proceeded in a stable manner. These observations are consistent with the above analysis and the fact that relatively high yield stresses are expected for the investigated epoxy systems far below $T_{\mathrm{g}}$ and at the high loading rates associated with the cyclic contact loading.

In Fig. 20, the maximum calculated values of $K_{\mathrm{I}}$ are reported as a function of the crack length under a constant amplitude tangential loading. As the crack length increases, the maximum value of $K_{\mathrm{I}}$ is progressively increased up to the experimental value of the bulk fracture toughness $\left(K_{\mathrm{IC}}=1.2 \mathrm{MPa} \mathrm{m}^{1 / 2}\right.$ according to [74]). Accordingly, the simulation indicates that a transition from stable to unstable crack propagation should occur during the course of a contact fatigue experiment, which is consistent with the above-reported experimental observations. Taking into account the experimental value of

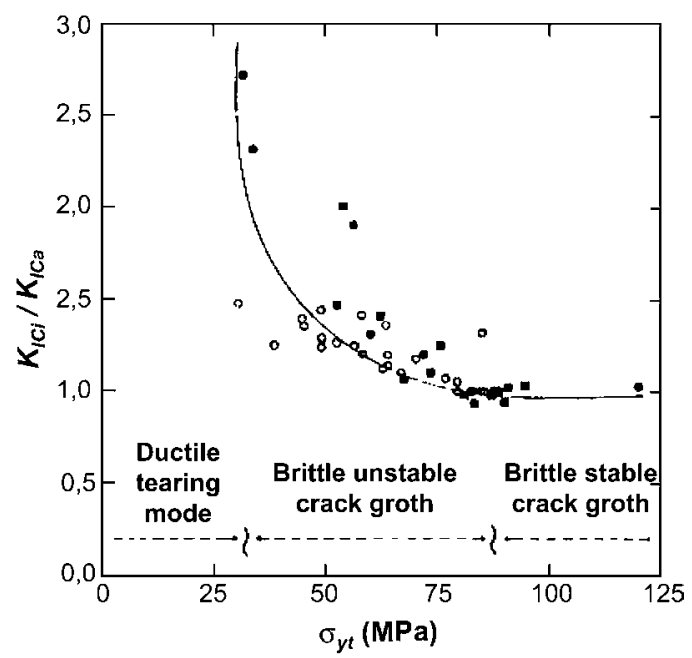

Fig. 19 Correlation between the ratio of the stress intensity factor to crack initatiation $\left(K_{\mathrm{ci}}\right)$ to stress intensity factor at crack arrest $\left(K_{\mathrm{ca}}\right)$ and the true yield stress $\left(\sigma_{\mathrm{yt}}\right)$ of epoxy materials (from [73]) 


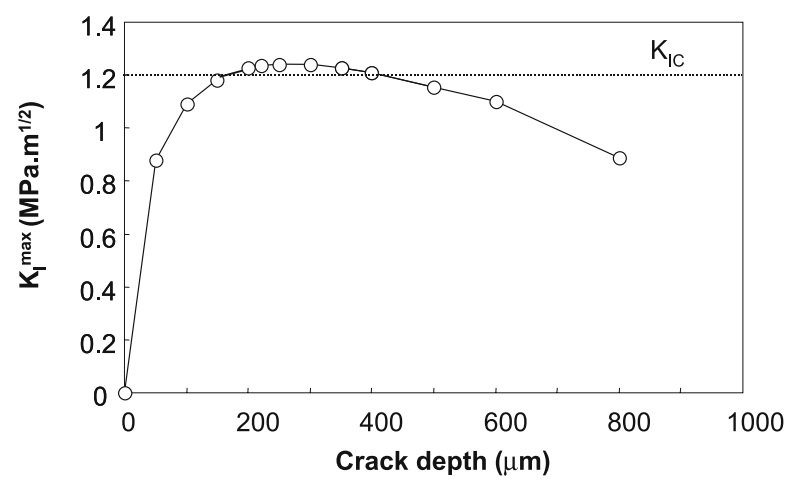

Fig. 20 Calculated maxima in the mode I stress intensity factor as a function of crack depth for a DGEBA/IPD epoxy material under cyclic loading. The dotted line corresponds to the experimental value of the mode I fracture toughness

the toughness, the calculation indicates that this transition should occur for a critical crack depth of about $200 \mu \mathrm{m}$, which closely matches experimental values.

4

\section{The Role of Molecular Parameters in Contact Fracture Processes of Glassy Polymers}

\section{1}

\section{Toughened Epoxy Networks}

The results described above clearly show that the intrinsic low fracture toughness of highly cross-linked epoxy networks can be a severe limitation in tribological applications involving contact fatigue conditions. Some attempts have been made, however, to assess the potential of toughened epoxy systems in order to improve the wear resistance of these materials. The addition of rubbers or thermoplastics which are initially miscible in the epoxy system and display a phase separation during curing (RIPS) has been recognized as an efficient route for toughening epoxies $[75,76]$. Carboxyl and amine terminated butadiene acrylonitrile (CTBN and ATBN, respectively) rubbery particles in particular proved to be successful in improving fracture behaviour but at the price of a substantial decrease in the thermo-mechanical properties due to the incorporation of the rubber phase into the epoxy matrix $[77,78]$. Moreover, these elastomers have relatively high glass transition temperatures which limit their low temperature flexibility. To overcome this limitation, siloxane elastomers emerged as an attractive alternative because they have glass 
transition temperatures well below those of CTBN and ATBN. When incorporated into highly cross-linked epoxy networks, poly(dimethylsiloxane) and poly(dimethyl-co-diphenyl) particles were found to induce a substantial increase in the wear resistance [79-81]. The formation of contact cracks within the siloxane-modified epoxies appears, however, to be strongly influenced by the size and the distribution of the micrometre-scale rubber domains which segregate during curing. When the domains are large and closely packed, there is some evidence that particle detachment processes result from the localization of the crack paths at the particle/matrix interface [80]. For the classical pin-on-disk tribological test configurations considered in these investigations, the wear rates roughly correlated with the inverse of the fracture toughness. The precise identification of the contribution of fracture toughness to the observed improvement in wear properties is, however, complicated by the lubricating action of polysiloxane-containing wear debris, which accumulates at the sliding interface during the course of the wear process. As a consequence, the magnitude of the cyclic stresses induced within the substrate is reduced and it is not clear whether the enhancement of the wear properties results from the improvement of the intrinsic fracture properties rather than from the modification of the friction-induced surface tractions.

Some more detailed answers to this question were recently provided within the context of the analysis of the contact fatigue behaviour of antiplasticized epoxy networks [82]. Anti-plasticizing agents usually consist of small molecule additives that can be incorporated into epoxy networks in order to increase the room temperature modulus. This latter effect has been shown to result from a decrease in the mechanical losses associated with the sub- $T_{\mathrm{g}} \beta$ relaxation, by virtue of the partial hindrance of the associated molecular motions by the additives molecules $[83,84]$. In addition, the selection of specific anti-plasticizing additives with a reduced miscibility in the epoxy resin can also yield an improvement in fracture properties. Bearing in mind that epoxy network toughening systematically results from phase separation, an appropriate tuning of the additive polarity allows selection of molecules that are initially miscible in the monomer mixture, but give rise to nanoscale phase separation during curing. Such a goal was achieved by Sauvant et al. $[85,86]$ by incorporating acetamide derivates in epoxy formulations based on diglycidylether of bisphenol A (DGEBA) fully cured in the presence of a stoichiometric amount of aromatic diamine (Table 1). In addition to an increased room temperature modulus, these formulations also exhibited a twofold increase in the room temperature fracture toughness (Table 2).

The contact fatigue behaviour of these modified epoxy networks was investigated under small amplitude micromotions. Under similar contact loading conditions, no cracks were detected within an anti-plasticized DGEBA/DDM network up to $5 \times 10^{3}$ cycles, whereas early crack propagation was detected in the unmodified network. Although some slight wear degradation was ob- 
Table 1 Formulae of the modified stoichiometric epoxy networks

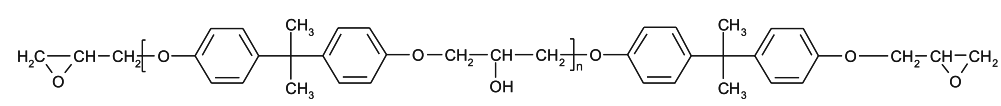

DGEBA

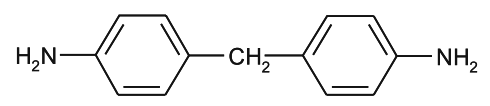

DDM

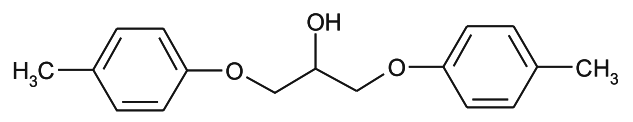

Acetamide derivative (AM)

Table 2 Mechanical and physical properties of the unmodified and modified DGEBA/DDM epoxy polymers. Data taken from [85, 86]. AM Acetamide derivative (see Table 1)

\begin{tabular}{lllll}
\hline & $T_{\mathrm{g}}\left({ }^{\circ} \mathrm{C}\right)^{\mathrm{a}}$ & $E^{\prime}(\mathrm{MPa})^{\mathrm{b}}$ & $\sigma_{\mathrm{y}}(\mathrm{MPa})^{\mathrm{c}}$ & $K_{\mathrm{IC}}\left(\mathrm{MPa} \mathrm{m}^{1 / 2}\right)^{\mathrm{d}}$ \\
\hline DGEBA/DDM & 190 & 2800 & 100 & 0.8 \\
DGEBA/DDM-AM & 111 & 3400 & 110 & 2.1 \\
\hline
\end{tabular}

${ }^{\text {a }}$ Measured from the maximum of the loss modulus $E^{\prime \prime}$ at $1 \mathrm{~Hz}$ using dynamic mechanical analysis

b Conservation modulus measured at $25^{\circ} \mathrm{C}$ and $1 \mathrm{~Hz}$

${ }^{c}$ Compressive yield stress measured at a strain rate of $2 \times 10^{-3} \mathrm{~s}^{-1}$

$\mathrm{d}$ Mode I Fracture toughness from notched three point bending specimens

served within the contact area (Fig. 21), the epoxy network with the included additive can be considered as essentially undamaged at the end of the fretting tests.

A relevant analysis of these differences in terms of toughness requires, however, that the local stress conditions at the crack nucleation sites are properly evaluated. Owing to changes in the modulus and/or frictional behaviour of the modified epoxy material, different stress conditions can be achieved locally in the contact and the improved crack resistance of modified epoxy does not necessarily reflect a change in its intrinsic crack propagation resistance. Regarding the magnitude of the tensile stresses generated at the edge of the contact, two opposite effects came into play: (1) an increase in the contact pressure due to the "fortified" modulus of the anti-plasticized material (from an Hertzian contact analysis, the quasi-static Young's moduli of the 


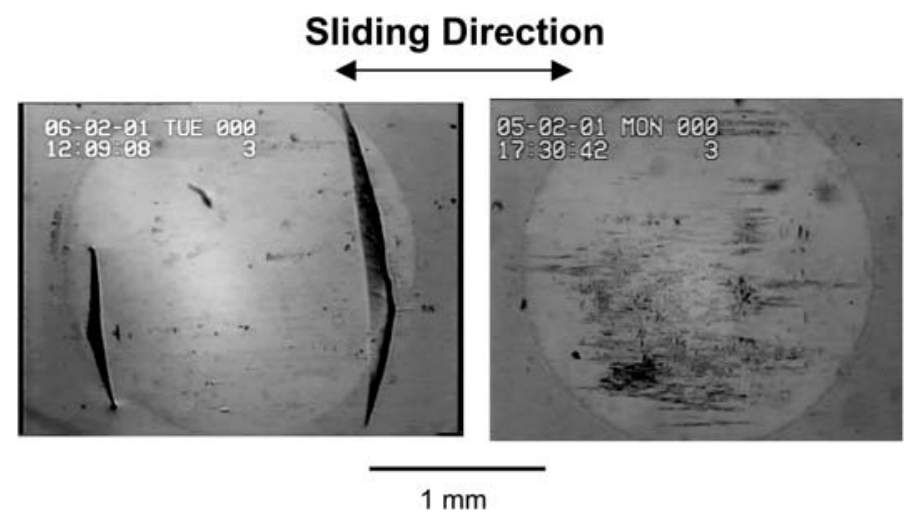

Fig. 21 In situ visualization pictures showing damage $\mathbf{a}$ in a fretting contact between an unmodified DGEBA/DDM epoxy network and a glass sphere, and $\mathbf{b}$ in a similar contact with a DGEBA/DDM network modified with the acetamide derivative shown in Table 1. The magnitude of the maximum tensile stress at the edge of the contact was found to be similar in both cases. Contact fatigue cracks were only observed in the neat DGEBA/DDM system

unmodified and modified epoxy networks were found to be $2600 \mathrm{MPa}$ and $3300 \mathrm{MPa}$ respectively), and (2) a slight decrease in the coefficient of friction in the case of the anti-plasticized network (from 1.2 to about 1.1). It turned out that these two effects compensated to give roughly the same value of the maximum tensile stress amplitude at the edge of the contact when crack nucleation was detected. Accordingly, the improved contact fatigue resistance of the anti-plasticized networks can be unambiguously attributed to their intrinsic toughening. Tentatively, a realistic mechanism might involve stress concentration localized in the nanophase domains which is able to favour plastic flow and dissipation at the crack tip, in agreement with the accepted toughening mechanism involved in rubber-toughened epoxy systems.

\section{2}

\section{Copolymers of Methylmethacrylate}

Random copolymers of methylmethacrylate (MMA) also provide a convenient way to investigate the contribution of molecular parameters to the contact fatigue behaviour of glassy amorphous polymers. Extensive mechanical characterization by Halary and co-workers [87-92] showed that the incorporation of various amounts of glutarimide or $\mathrm{N}$-substituted maleimide units as a co-monomer of MMA (Table 3) can result in strong changes in the plastic behaviour and deformation modes. At the molecular level, these modifications were mostly attributed to changes in the cooperative motions involved in the temperature range situated immediately above the sub- $T_{\mathrm{g}} \beta$ relaxation, which are considered precursors of the $\alpha$-relaxation [90]. Addition of increas- 
Table 3 Formulae of the random copolymers of methylmethacrylate

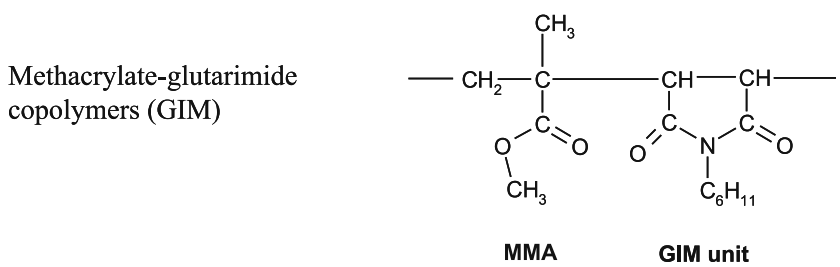

Methacrylate-maleimide copolymers (MIM)

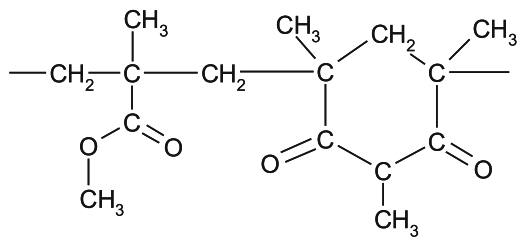

MMA

MIM unit

ing amounts of maleimide was shown to induce a decoupling of the $\alpha$ and $\beta$ relaxation, which was associated with a marked embrittlement of the materials. Conversely, increased contents in glutarimide units tended to enhance the cooperative motions involved in yielding with some consequences on the competition between scission crazing, shear deformation and disentanglement crazing in these materials [92]. Homologous series of MMA-glutarimide (GIM) or MMA-maleimide (MIM) copolymers therefore offer the possibility of tuning the fracture properties from a ductile to a brittle behaviour, while keeping the elastic and plastic properties almost unchanged (Table 4).

A systematic investigation of the contact fatigue behaviour of the GIM and MIM copolymers has been carried out at various imposed normal loads within the elastic range of the polymers [93]. Whatever the contact load, a strong difference was observed in the development of the crack networks for the two materials (Fig. 22). For the MIM system, the nucleation of cracks at the edge of the contact area was immediately followed by a brittle propagation stage. In contrast, crack propagation within the GIM copolymer occurred in a much more progressive manner and multiple crack initiation was often observed.

Crack propagation within MIM was also associated with a slight but perceptible decrease in the contact tangential stiffness, which was not the case for the GIM copolymer. As reported above, the contact stiffness is strongly sensitive to the extent of crack propagation. The fact that a drop in contact stiffness is not perceptible for the GIM polymer could therefore be interpreted as evidence of a limited propagation of the surface cracks through the thickness of the specimens. 
Table 4 Mechanical and physical properties of the methylmethacrylate-based random copolymers. GIM 76 is a copolymer containing $76 \%$ of glutarimide units, MIM 25 a copolymer containing $25 \%$ maleimide units. Data taken from [89, 90, 98]

\begin{tabular}{llllll}
\hline & $T_{\mathrm{g}}\left({ }^{\circ} \mathrm{C}\right)^{\mathrm{a}}$ & $E^{\prime}(\mathrm{MPa})^{\mathrm{b}}$ & $\sigma_{y}(\mathrm{MPa})^{\mathrm{c}}$ & $K_{\mathrm{IC}}\left(\mathrm{MPa} \mathrm{m}^{1 / 2}\right)$ & $H(\mathrm{MPa})$ \\
\hline GIM 76 & 158 & 3400 & 120 & $2.4^{\mathrm{d}}$ & 260 \\
MIM 25 & 161 & 3000 & 125 & $0.85^{\mathrm{f}}$ & 250 \\
\hline
\end{tabular}

a, b, c, d As for Table 2

${ }^{\mathrm{d}}$ As for Table 2. Measured using nano-indentation at a constant average strain rate of $0.05 \mathrm{~s}^{-1} .{ }^{\mathrm{f}}$ Estimated from the fretting tests (see text)

Interestingly, the ductile-brittle transition observed for the MIM system provided an opportunity to assess the material fracture toughness, which was not possible using classical fracture mechanics tests due to the intrinsic brittleness of the MIM system. The measurement of the critical crack length, $L_{\mathrm{c}}$, in the contact plane at the onset of brittle propagation allows estimation of a fracture toughness $K_{\mathrm{IC}}=\sigma_{\mathrm{xx}}^{\max } \sqrt{\pi L_{\mathrm{c}}}$ in the order of $0.85 \mathrm{MPa} \mathrm{m}^{1 / 2}$, i.e. much less than that of a poly(methylmethacrylate) homopolymer $\left(1.20 \mathrm{MPa} \mathrm{m}^{1 / 2}\right)$.

As for the epoxy polymers, a quantitative comparison of the contact fatigue behaviour was attempted on the basis of an estimate of the maximum tensile stress at the edge of the contact. The coefficient of friction of the copolymers increased as the tests proceeded, with a variation which was dependent upon the level of the normal loading. As a first approach, the value of $\mu$ at crack initiation was taken into account in the calculation of $\sigma_{\mathrm{xx}}^{\max }$. The results are reported in a " $S$ - $N$ " fatigue diagram giving the maximum applied tensile stress as a function of the number of cycles to crack initiation (Fig. 23). These data show a marked increase in the contact fatigue resistance of the GIM copolymers compared with the MIM material.

The observed contact cracking mechanisms are interesting to compare to previously reported investigations of the microdeformation mechanisms of thin films of the same copolymers strained in tension and observed by transmission electron microscopy $[90,92]$. Depending upon the temperature and the composition of the methylmethacrylate copolymers, competitive deformation processes in the form of crazes or homogeneous shear deformation zones were identified. For the MIM copolymer under investigation, extensive craze formation was observed at room temperature as a result of the embrittlement of the copolymers by the maleimide co-monomers. In contrast, straining of the GIM copolymer thin films at $20^{\circ} \mathrm{C}$ resulted in the extensive formation of shear bands in addition to crazes (as a comparison poly(methylmethacrylate) shows predominantly crazes under comparable conditions). This behaviour reflects the increased plastic yielding ability, or ductility, of the GIM copolymer and has a strong beneficial ef- 
(a)

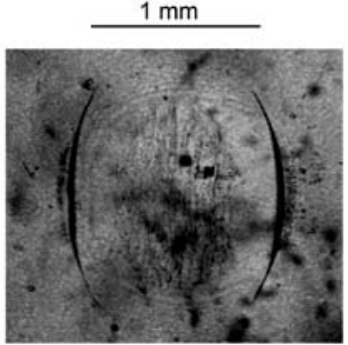

400 cycles

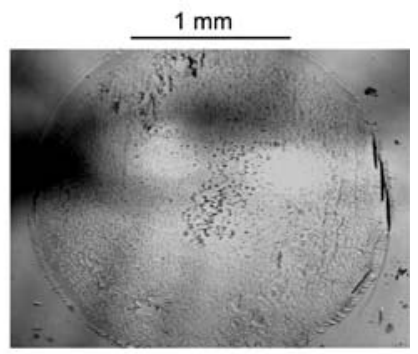

660 cycles

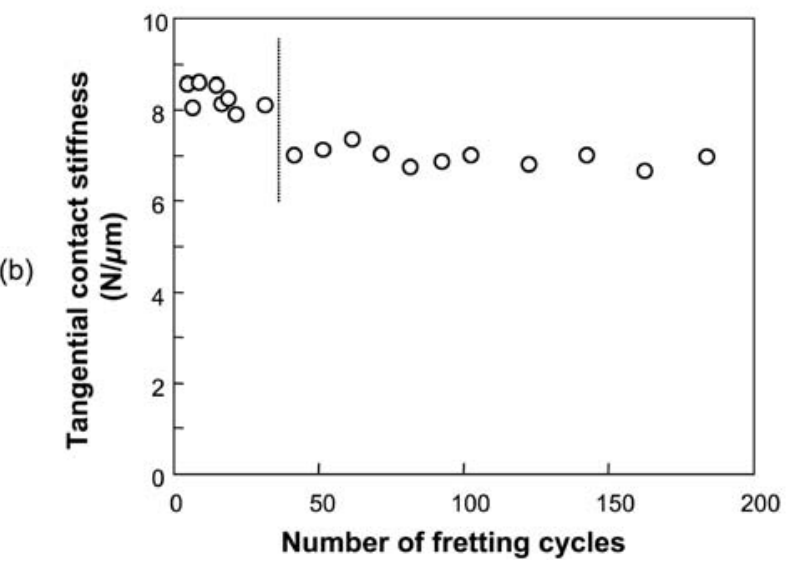

Fig. 22 Contact cracking processes within random copolymers of methylmethacrylate under fatigue conditions (from [93]). a In situ observation of the contact areas. b Changes in the contact stiffness as a function of the number of cycles for the cyclohexyl maleimide system (see Table 2). Crack propagation is associated with a drop in contact stiffness as indicated by the dotted line. In the case of the glutarimide system, no significant change in contact stiffness was detected after contact cracking

fect on the macroscopic fracture toughness, which is about twice that of poly(methylmethacrylate).

These conclusions are intersting in the light of the investigations by Yang et al. on the role of craze breakdown during the fracture processes involved in abrasive wear in glassy polystyrene and blends of polystyrene and poly(phenylene oxide) $[39,40]$. Using series of monodisperse polystyrenes with increasing molecular weight, these authors showed a correlation between the craze breakdown strain measured using thin films and the abrasive wear resistance of the polymer. Similar trends were also observed when the craze breakdown strain was modified by incorporating various amounts of low molecular weight polystyrene into the high molecular weight polystyrene material. The use of fully miscible blend systems of craze forming polystyrene and ductile poly(phenylene oxide) also provided the possibility of investigat- 


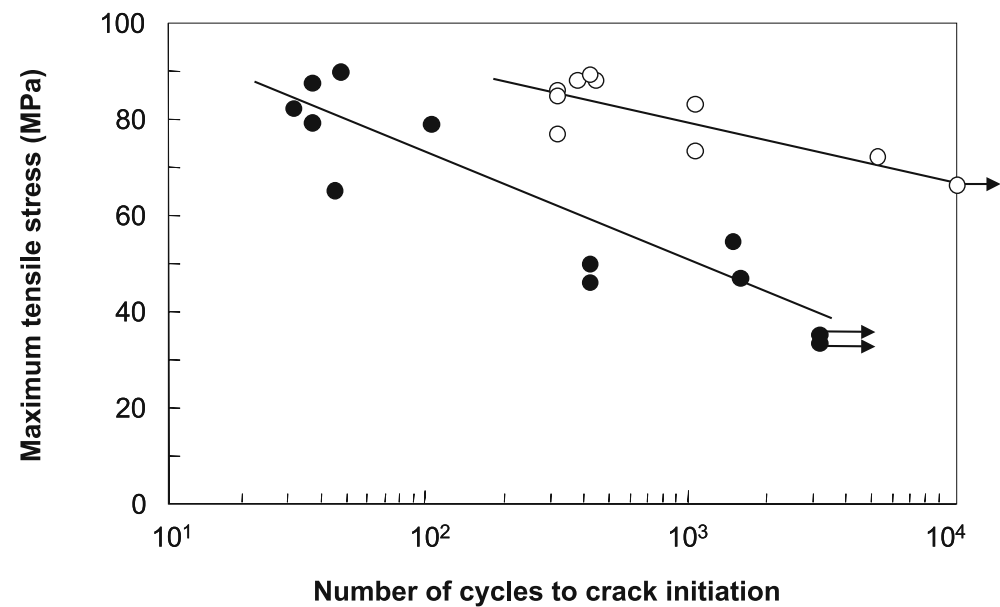

Fig. 23 Contact fatigue behaviour of methylmethacrylate random copolymers under fretting conditions. White circle Glutarimide co-monomer (76\%), black circle cyclohexyl malemimide co-monomer (25\%). The maximum value of the tensile stress has been calculated at the edge of the contact, where cracks initiate, and for values of the coefficient of friction measured at crack initiation

ing the effects on wear behaviour of brittle-ductile transitions from crazing to shear yielding. An examination of the wear-composition dependence of these systems showed the existence of two wear regimes delimited by the known composition for crazing-shear yielding transition. Accordingly, Yang et al. concluded that the wear transition resulted from a change from craze-dominated abrasive wear processes at low poly(phenylene oxide) contents to a behaviour where shear zones became the prevalent microdeformation mechanism. These experimental observations tend to support the idea that deformation and fracture modes during asperity scratching of polymeric glasses is strongly controlled by a competition between crazing processes and shear yielding. It also suggests that craze criteria could be adequately be incorporated in a contact mechanics analysis of crack nucleation in PS and acrylate polymers. Interestingly, it can be noted that usual craze nucleation criteria incorporate the effect of hydrostatic pressure $[94,95]$ which can be shown to be maximum at the leading edge of the contact where cracks nucleate.

\section{5}

\section{Conclusion}

Extensive in situ observations of failure processes within model single asperity contacts demonstrate the relevance of fracture mechanics approaches to the analysis of cracking processes within sliding contacts involving brit- 
tle amorphous polymers. Under predominantly elastic conditions, it turns out that key parameters such as crack location, orientation and propagation depth can adequately be predicted from a knowledge of the bulk material fracture properties (toughness, fatigue) and a detailed analysis of the contact stress field and stress intensity factors. This conclusion tends to support the overall validity of a fracture mechanics approach to the quantitative analysis of initial particles detachment processes involved in the wear of brittle polymers. The incorporation of fracture mechanics ingredients into realistic wear models would naturally require that interactions between multiple cracks are taken into account. On the basis of the available description of single-crack propagation mechanisms, there is, however, no obvious objection to the extension of the current fracture mechanics approach to more realistic situations involving the development of a complete crack network within a sliding contact.

The combination of experimental and theoretical approaches to contact cracking processes was also applied to homologous series of polymers differing in their microstructural characteristics or by the presence of low molecular weight additives. It allowed a clear distinction between the separate contributions of intrinsic toughness properties and frictional properties to the observed changes in the contact cracking behaviour. Such an approach could provide some guidelines for the development of wear-resistant polymer formulations in situations where brittle cracking is the dominant tribological damage mechanism.

One of the outstanding problems related to contact cracking in brittle polymers remains the complex interactions between crack nucleation processes and surface modifications due to frictional sliding. In the above detailed fretting analysis, cracks were indeed induced by the contact stress field, but in a region (at the edge of the contact zone) where the polymer surface was not subjected to extensive frictional processes. The situation would be different under large amplitude sliding in the sense that cracks will be initiated in a surface layer extensively sheared during the frictional processes. Within this context the question of determination of the extent to which surface microstructural modifications due, for example, to cyclic plastic deformation, can affect crack nucleation processes arises. In contrast to metallic materials where the interactions between particle detachment processes and tribologically transformed surface layers has long been recognized, this field of investigation remains largely unexplored in polymer tribology.

\section{References}

1. Lancaster JK (1972) In: Jenkins AD (ed) Polymer science, a material science handbook, vol 2. North-Holland, London, pp 959-1042

2. Lancaster JK (1990) Wear 141:159 
3. Briscoe BJ, Sinha SK (2002) J Eng Tribol 216:401

4. Briscoe BJ (1990) Scripta Metall Mater 24:839

5. Briscoe BJ (1981) Tribol Int 14:231

6. Briscoe BJ, Chateauminois A (1998) In: Vincent L (ed) Matériaux et contacts. Presses Polytechniques et Universitaires Romandes, Lausanne, pp 197-208

7. Bowden FP, D Tabor (1958) The friction and lubrication of solids. Clarendon, Oxford

8. Bahadur S (2000) Wear 245:92

9. Proceedings of the Royal Society of London - Series A, 1972, 329 (1578), p 251

10. Tanaka K, Miyata T (1977) Wear 41:383

11. Hironaka S (1995) Sekiyu Gakkaishi 38:137

12. Plummer CJG, Kausch H-H (1996) Polym Bull 37:393

13. Plummer CJG, Kausch HH (1997) Sen'i-Gakkaishi 53:555

14. Li TQ, Zhang MQ, Song L, Zeng HM (1999) Polymer 40:4451

15. Ratner SN, Farberoua II, Radyukeuich OV, Lure EG (1964) Soviet Plastics 7:37

16. Lancaster JK (1969) Tribology Convention. Institute of Mechanical Engineers, London p 100

17. Atkins AG, Omar MK, Lancaster JK (1984) J Mater Sci Lett 3:779

18. Jain VK, Bahadur S (1980) Wear 60:237

19. Jain VK, Bahadur S (1982) Wear 79:241

20. Berthier Y, Kapsa P, Vincent L (1998) In: Vincent L (ed) Matériaux et contacts. Presses Polytechniques et Universitaires Romandes, Lausanne

21. Godet M (1984) Wear 100:437

22. Briscoe BJ, Chateauminois A, Lindley TC, Parsonage D (1998) Tribol Int 31:701

23. Briscoe BJ, Chateauminois A, Parsonage D, Lindley TC (2000) Wear 240:27

24. Chateauminois A, Briscoe BJ (2003) Surf \& Coatings Technol 163:435

25. Briscoe BJ (1998) Tribol Int 31:121

26. Friedrich K (1998) In: Friedrich K (ed) Advances in composite tribology. (Composite materials series), vol 8. Elsevier, Amsterdam p 209

27. Tewari US, Bijwe J (1993) In: Friedrich K (ed) Advances in composite tribology. (Composite materials series), vol 8. Elsevier, Amsterdam p 159

28. Schottner G, Rose K, Posset U (2003) J Sol-Gel Sci Technol 27:71

29. Stojanovic S, Bauer F, Glasel HJ, Mehnert R (2004) Prog Adv Mater Processes (Mater Sci Forum) 453-454:473

30. Mehnert R, Hartmann E, Glasel HJ, Rummel S, Bauer F, Sobottka A, Elsner C (2001) Materialwissenschaft Werkstofftechnik 32:774

31. Schallamach A (1971) Wear 17:301

32. Tabor D (1951) The Hardness of Metals. Oxford University Press, New York

33. Briscoe BJ, Fiori L, Pelillo E (1998) Journal of Physics D: Applied Physics 31:2395

34. Briscoe BJ, Pelillo E, Sinha SK (1996) Polymer Engineering and Sci 36:2996

35. Briscoe BJ, Evans PD, EP, Sinha SK (1996) Wear 200:137

36. Briscoe BJ, Pelillo E, Sinha SK (1997) Polymer International 43:359

37. Briscoe BJ, Sinha SK (2003) Materialwiss Werkstofftech 34:989

38. Xiang C, Sue HJ, Chu J, Coleman B (2000) J Polym Sci: Part B: Polymer Physics 39:47

39. Yang ACM, Wu TW (1993) J Mater Sci 28:955

40. Yang ACM, Wu TW (1997) J Polym Sci B: Polym Phys 35:1295

41. Jardret V, Morel P (2003) Prog Org Coatings 48:322

42. Hamilton GM (1983) Proc Inst Mech Eng 197C:53

43. Bucaille JL, Felder E, Hochstetter G (2001) Wear 249:422

44. Bucaille JL, Felder E (2002) Philos Mag A-Phys Condensed Matter Struct Defects Mech Properties 82:2003 
45. Bertrand-Lambotte P, Loubet JL, Verpy C, Pavan S (2001) Thin Solid Films 398399:306

46. Bertrand-Lambotte P, Loubet JL, Verpy C, Pavan S (2002) Thin Solid Films 420421:281

47. Puttick KE (1980) J Phys D: Appl Phys 13:2249

48. Puttick KE, Yousif RH (1983) J Phys D: Appl Phys 16:621

49. Gauthier C, Lafaye S, Schirrer R (2001) Tribol Int 34:469

50. Gauthier C, Schirrer R (2000) J Mater Sci 35:2121

51. Zhang HQ, Sadeghipour K, Baran G (1999) Wear 224:141

52. Sadeghipour K, Baran G, Zhang HQ, Wu W (2003) J Eng Mater Technol Trans Asme 125:97

53. Chateauminois A, Kharrat M, Krichen A (2000) In: Chandrasekaran V, Elliott CB (eds) Fretting fatigue: current technology and practices, ASTM STP 1367. American Society for Testing and Materials, West Conshohocken, p 325

54. Mindlin RD (1953) ASME Trans J Appl Mech, Ser E 16:327

55. Johnson KL (1985) Contact mechanics. Cambridge University Press, Cambridge, UK

56. Kharrat M, Krichen K, Chateauminois A (1999) Tribol Trans 42:377

57. Vincent L (1994) Fretting fatigue ESIS 18. Mechanical Engineering Publications, London, $\mathrm{p} 323$

58. Fouvry S, Kapsa P, Vincent L (1996) Wear 200:186

59. Cattaneo C (1938) Rend Accad Lincei 6:343

60. Nagasawa M, Kinuhata H, Koizuka H, Miyamoto K, Tanaka T, Kishimoto H, Koike T (1995) J Mater Sci 30:1266

61. Lorenzo L, Hahn HT (1986) Polym Eng Sci 26:274

62. Rabinowitz S, Beardmore P (1974) J Mater Sci 9:81

63. Lesser AJ, Kody RS (1997) J Polym Sci B: Polym Phys 35:16

64. Kody RS, Lesser AJ (1997) J Mater Sci 32:5637

65. Dubourg MC, Chateauminois A, Villechaise B (2003) Tribol Int 36:109

66. Kalker JJ (1990) Three dimensional elastic bodies in rolling contact. Kluwer, Dordrecht

67. Lawn B (1993) Fracture of brittle solids, 2nd edn. Cambridge University Press, Cambridge, UK

68. Dubourg MC, Villechaise B (1992) ASME J Tribol 114:462

69. Dubourg MC, Villechaise B (1989) Eur J Mech A 8:309

70. Dubourg MC, Villechaise B (1992) ASME J Tribol 114:455

71. Yamini S, Young RJ (1980) J Mater Sci 15:1823

72. Phillips DC, Scott JM, Jones M (1978) J Mater Sci 13:311

73. Vakil UM, Martin GC (1993) J Mater Sci 28:4442

74. Urbaczewski-Espuche E, Galy J, Gerard JF, Pascault JP, Sautereau H (1991) Polym Eng Sci 31:1572

75. Williams RJJ, Rozenberg B, Pascault JP (1997) Adv Polym Sci 128:1

76. Sultan JN, McGarry FJ (1973) Polym Eng Sci 13:29

77. Becu L, Sautereau H, Maazouz A, Gerard JF, Pabon M, Pichot C (1994) Polym Adv Technol 6:316

78. Verchere D, Pascault JP, Sautereau H, Moschiar SM, Riccardi CC, Williams J (1991) J Appl Polym Sci 42:701

79. Rey L, Poisson N, Maazouz A, Sautereau H (1999) J Mater Sci 34:1775

80. Chitsaz-Zadeh MR, Eiss NS (1990) Tribol Trans 33:499

81. Eiss NS, Czichos H (1986) Wear 111:347

82. Chateauminois A, Sauvant V, Halary JL (2003) Polym Int 52:507 
83. Heux L, Lauprêtre F, Halary JL, Monnerie L (1998) Polym 39:1269

84. Merritt ME, Goetz JM, Whitney D, Chang CPP, Heux L, Halary JL, Schaefer J (1998) Macromolecules 31:1214

85. Sauvant V, Halary JL (2001) J Appl Polym Sci 29:759

86. Sauvant V, Halary JL (2002) Composites Sci Technol 62:481

87. Halary JL, Monnerie L, Kausch HH (2005) In: Kausch HH (ed) Intrinsic molecular mobility and toughness of polymers. (Advances in polymer science). Springer, Berlin Heidelberg New York 187:215

88. Laupretre F, Monnerie L, Halary JL (2005) In: Kausch HH (ed) Intrinsic molecular mobility and toughness of polymers. (Advances in polymer science). Springer, Berlin Heidelberg New York 187:35

89. Tordjeman P, Halary JL, Monnerie L, Donald AM (1995) Polymer 36:1627

90. Tordjeman P, Teze L, Halary JL, Monnerie L (1997) Polym Eng Sci 37:1621

91. Teze L, Halary JL, Monnerie L, Canova L (1999) Polymer 40:971

92. Plummer CJG, Kausch H-H, Teze L, Halary JL, Monnerie L (1996) Polymer 37:4299

93. Lamethe JF, Sergot P, Briscoe BJ, Chateauminois A (2003) Wear 255:758

94. Argon AS, Hannoosh JG (1977) Philos Magazine 36:1195

95. Estevez R, Van der Giessen E (2005) In: Kausch HH (ed) Intrinsic mobility and toughness of polymers. (Advances in Polymer Science). Springer, Berlin Heidelberg New York 188:195

96. Briscoe BJ (1998) In: Friedrich K (ed) Advances in composite tribology (composite materials series), vol 8. Elsevier, Amsterdam, p 3

97. Dubourg MC, Chateauminois A (2002) In: Williams JG (ed) Fracture of polymers, composites and adhesives (ESIS TC4) (ESIS publication 32). Elsevier, Les Diablerets, Switzerland, p 51

98. Teze L, Halary JL, Monnerie L, Canova L (1998) Polymer 40:971 